University of Nebraska - Lincoln

DigitalCommons@University of Nebraska - Lincoln

U.S. National Park Service Publications and

Papers

National Park Service

$2-18-2020$

\title{
Implications of Organic Mass to Carbon Ratios Increasing Over Time in the Rural United States
}

W.C. Malm

Colorado State University, Fort Collins, wc.malm@colostate.edu

B.A. Schichtel

National Park Service, Air Resources Division

J.L. Hand

Colorado State University, Fort Collins

A.J. Prenni

National Park Service, Air Resources Division

Follow this and additional works at: https://digitalcommons.unl.edu/natlpark

Part of the Environmental Education Commons, Environmental Policy Commons, Environmental Studies Commons, Fire Science and Firefighting Commons, Leisure Studies Commons, Natural Resource Economics Commons, Natural Resources Management and Policy Commons, Nature and Society Relations Commons, Other Environmental Sciences Commons, Physical and Environmental Geography Commons, Public Administration Commons, and the Recreation, Parks and Tourism Administration Commons

Malm, W.C.; Schichtel, B.A.; Hand, J.L.; and Prenni, A.J., "Implications of Organic Mass to Carbon Ratios Increasing Over Time in the Rural United States" (2020). U.S. National Park Service Publications and Papers. 208.

https://digitalcommons.unl.edu/natlpark/208

This Article is brought to you for free and open access by the National Park Service at DigitalCommons@University of Nebraska - Lincoln. It has been accepted for inclusion in U.S. National Park Service Publications and Papers by an authorized administrator of DigitalCommons@University of Nebraska - Lincoln. 


\section{JGR Atmospheres}

\section{RESEARCH ARTICLE 10.1029/2019JD031480 \\ Implications of Organic Mass to Carbon Ratios Increasing Over Time in the Rural United States}

Key Points:

- Explanations are presented for the increase in organic carbon to carbon mass over the last 10 years

- Carbon thermal evolution analytic techniques inaccurately bifurcate evolved carbon into the organic and light-absorbing fractions

- A first-order model is presented to separate charred or pyrolyzed carbon from native light absorbing carbon

Correspondence to:

W. C. Malm,

wc.malm@colostate.edu

Citation:

Malm, W. C., Schichtel, B. A., Hand, J. L., \& Prenni, A. J. (2020). Implications of organic mass to carbon ratios

increasing over time in the rural United States. Journal of Geophysical Research: Atmospheres, 125, e2019JD031480. https://doi.org/10.1029/2019JD031480

Received 19 AUG 2019

Accepted 17 FEB 2020

Accepted article online 18 FEB 2020

\author{
W. C. Malm ${ }^{1}$, B. A. Schichtel ${ }^{2}$ D, J. L. Hand ${ }^{1}$ (D) and A. J. Prenni ${ }^{2}$ iD \\ ${ }^{1}$ Cooperative Institute for Research in the Atmosphere, Colorado State University, Fort Collins, CO, USA, ${ }^{2}$ National Park \\ Service, Air Resources Division, Lakewood, CO, USA
}

\begin{abstract}
The thermal evolution procedure used by most monitoring programs in the United States to determine carbonaceous aerosol concentrations is referred to as the thermal-optical reflectance method, where an aerosol sample that has been collected on a quartz filter is heated and evolved carbon is characterized as either organic (OC) or light absorbing carbon (LAC). Evolved carbon assigned to OC is multiplied by a factor, $R_{\mathrm{oc}}$, to achieve an estimate of organic mass. Over the last 10-15 years, $R_{\mathrm{oc}}$, estimated through multiple linear regression analysis of data collected in the Interagency Monitoring of Protected Visual Environments (IMPROVE) program, has increased at about a rate of about 0.02 per year, reaching values above 2.0 in many regions of the United States. Analysis of evolved carbon concentration temporal trends suggests that thermal-optical reflectance analysis, on the average, inaccurately bifurcates particulate carbon into the OC and LAC fractions with some LAC being inadvertently and wrongly assigned to the OC fraction. It is shown that misapportioned LAC assigned to OC is decreasing faster than true OC, resulting in a compensating increase in the $R_{\mathrm{oc}}$ assigned to reported OC over time. A first-order model is proposed to correct for the misapportioned carbon.
\end{abstract}

\section{Introduction}

Carbonaceous aerosols make up a substantial fraction of atmospheric particulate loading, ranging from averages of about $60 \%$ in parts of the western United States to $25-40 \%$ in the East (Hand et al., 2013; Malm et al., 2017). Typically, carbonaceous aerosols are categorized into operationally defined organic carbon (OC) and elemental carbon (EC) components and sometimes inorganic carbon in the form of calcium carbonate (Cao et al., 2003; Chow et al., 1993, 2005, 2006; Watson et al., 1994, 2005; Yu et al., 2002), all of which are of interest because of differing health, climate forcing, and visibility effects. In the literature, EC, black carbon (BC), soot, and light absorbing carbon (LAC) have often been used interchangeably (Bond \& Bergstrom, 2006), although Petzold et al. (2013) have recommended terminology to clarify the terms used in atmospheric research. Bond and Bergstrom (2006) and Malm et al. (1994) suggest using the term LAC to encompass all forms of carbonaceous material that absorb light, whether it be refractory carbon, such as carbon with a graphitic structure, or organic LAC, such as brown carbon found in smoke aerosols.

The most common analytic technique for estimating ambient carbon aerosol mass is the thermal evolution of carbon from particles that have been collected on quartz filters (Watson et al., 2005). Many thermal evolution procedures have been proposed over the years, and even as certain "standardized" thermal evolution techniques have been adopted, there is not one common definition of what constitutes LAC or OC. There have been at least 15 thermal combustion methods identified (Cadle et al., 1980; Fung, 1990; Huntzicker et al., 1982; Novakov, 1982; Tanner, 1982; Mizohata \& Ito, 1985; Cachier et al., 1989a, 1989b; Chow et al., 1993, 2001; Rupprecht et al., 1995; NIOSH, 1999; VDI (Verein Deutscher Ingenieure), 1999; Mader et al., 2001; Sharma et al., 2002; Yang \& Yu, 2002).

The Regional Haze Rule (U.S. EPA (U.S. Environmental Protection Agency), 1999) requires monitoring representative of 156 visibility-protected federal areas beginning in January 2001. This entails particle sampling and analysis of the major aerosol components using methods patterned after those used since 1987 by the Interagency Monitoring of Protected Visual Environments (IMPROVE) network (Joseph et al., 1987; Malm et al., 1994). To that end, the IMPROVE monitoring program has adopted an aerosol carbon analysis approach where the filter is heated in a nonoxidizing environment of helium ( $\mathrm{He}$ ) up to 


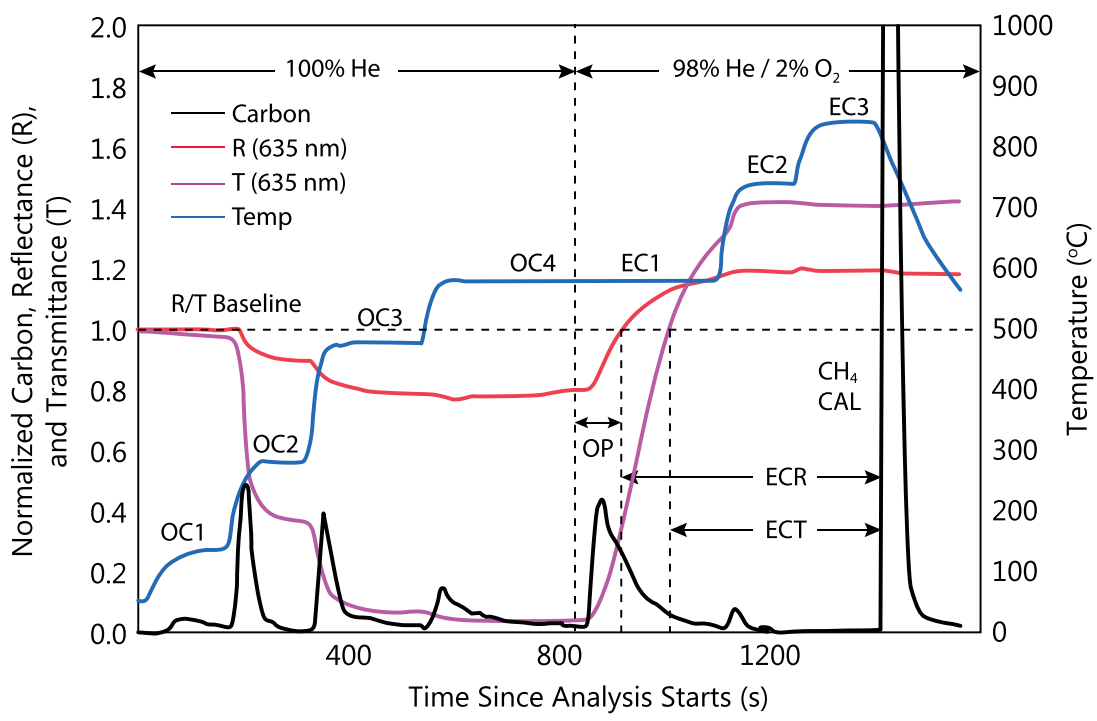

Figure 1. Typical thermogram showing the normalized evolved carbon signal, chamber temperature, laser reflectance and transmittance signals, and carbon concentration signals corresponding to $\mathrm{OC} 1, \mathrm{OC} 2, \mathrm{OC} 3, \mathrm{OC} 4, \mathrm{EC} 1, \mathrm{EC} 2$, and EC3. ECR and ECT refer to the assigned elemental carbon concentrations corresponding to the reflectance and transmittance signals, respectively. OP is that portion of EC1 that is interpreted as pyrolyzed carbon (Chow et al., 1993).

some temperature, typically $580{ }^{\circ} \mathrm{C}$ (Chow et al., 2007). Figure 1 shows a typical thermogram for this method (courtesy of DRI). The blue, black, red, and magenta lines correspond to sample environment temperature, evolved carbon, sample reflectance, and transmittance, respectively. When heated under an $\mathrm{He}$ environment, a fraction of organic aerosols char or pyrolyze, essentially converting OC into LAC. Then, an oxidizing environment containing $2 \% \mathrm{O}_{2}$ is introduced, resulting in both charred and native LAC evolving, labeled as the EC1 peak in Figure 1. Also shown in Figure 1 is the carbon that has evolved at various temperatures under $\mathrm{He}$, which are referred to as the $\mathrm{OC} 1\left(140{ }^{\circ} \mathrm{C}\right), \mathrm{OC}^{\circ}$ $\left(280{ }^{\circ} \mathrm{C}\right)$, OC3 $\left(580{ }^{\circ} \mathrm{C}\right)$, and $\mathrm{OC} 4\left(580{ }^{\circ} \mathrm{C}\right)$ peaks. Carbon evolved above about $580{ }^{\circ} \mathrm{C}$ is referred to as $\mathrm{EC} 2\left(740{ }^{\circ} \mathrm{C}\right)$ and $\mathrm{EC} 3\left(840{ }^{\circ} \mathrm{C}\right)$.

To account for the pyrolyzed carbon contained in the E1 peak, filter reflectance and/or transmittance is continuously monitored as the sample is heated in varying environments. The reflectance or transmittance eventually returns to its initial or baseline value. Carbon that evolves before reflectance or transmittance returns to its baseline value is interpreted as $\mathrm{OC}$, while the remaining carbon associated with the EC1 peak is assigned to the LAC fraction and is labeled as ECR or ECT in Figure 1. That portion of the EC1 peak that evolves before the reflectance or transmittance returns to its original value is referred to as OP or pyrolyzed carbon and is considered to be organic in nature. Any remaining fraction of the EC1 peak is considered LAC. Fractionating EC1 using the transmittance signal is referred to as the thermal- optical transmittance (TOT) measurement, while using the reflectance signal is referenced as thermal-optical reflectance (TOR). Therefore, $\mathrm{OC}=\mathrm{O} 1+\mathrm{O} 2+\mathrm{O} 3+\mathrm{O} 4+\mathrm{OP}=\mathrm{OL}+\mathrm{OP}$ and $\mathrm{LAC}=\mathrm{ECR}$. Here OL is defined as the sum of $\mathrm{O} 1, \mathrm{O} 2, \mathrm{O} 3$, and $\mathrm{O} 4$.

Assigning EC1 carbon to OP and LAC is predicated on the assumption that charred or pyrolyzed carbon evolves before native LAC or that optical characteristics of native LAC and pyrolyzed carbon are the same. A third assumption is that laser reflectance or transmittance is independent of filter loading.

Yang and $\mathrm{Yu}$ et al. (2002) point out that the evolution of charred and native LAC overlap, despite multiple stepwise combustion at temperatures varying from 575 to $910{ }^{\circ} \mathrm{C}$, that mass absorption efficiencies (MAE) of charred and native LAC as a function of carbon evolution are not the same, and that charred carbon MAEs vary during a single thermal analysis. Karanasiou et al. (2015) point out that the difference between reflectance and transmittance corrections tends to be larger than the difference between different thermal protocols. Chow et al. (2004), by making simultaneous TOT and TOR measurements, found that LAC determined by TOT is $30 \%$ lower than TOR for the same temperature protocol and $70-80 \%$ 
lower than TOR for a protocol with higher heating temperatures and shorter residence times. They suggest that due to charring of adsorbed gases within the filter, transmittance may be more affected than filter reflectance, causing a lower reported LAC fraction of EC1. Karanasiou et al. (2015) also state that the difference between EC values as determined by the different protocols is not only dependent on the optical pyrolysis correction method but also on the chemical properties of the samples due to different contributions from various sources.

Boparai et al. (2008) confirmed that release temperatures of charred carbon and LAC are similar, so temperatures cannot be used to differentiate these materials; that optical properties of charred and LAC vary greatly; and, also, that OC may be retained after introducing the He or inert atmosphere. Davy et al. (2017) point out that the relationship between light absorption and BC measured using the TOT method is nonlinear and differs by filter type and measurement method.

Boparai et al. (2008) attempted to develop a model that incorporates evolved carbon in combination with continuous filter transmittance measurements to unambiguously determine the OC-LAC split, independent of thermal evolution procedure. They conclude that despite this additional information, the TOT system of equations remains indeterminate, with more unknowns than constraining variables required to unambiguously quantify evolved carbon into OC and LAC.

There is not a methodology that clearly and unambiguously separates carbon into light absorbing and purely refractive components. Karanasiou et al. (2015) conclude from their literature review that it is not possible to identify the "best" thermal-optical protocol.

Typically, a standard is used, based on fundamental principles, that allows an instrumental output to be directly traceable to an analyte. Heating a sample to sustained high temperatures in the presence of enough oxygen to convert all its carbon to $\mathrm{CO}_{2}$ gas and then using some accepted method to quantify the evolved $\mathrm{CO}_{2}$ mass might provide such a standard for total carbon (TC). There are standards for EC (Long et al., 2013); however, they do not represent the complex mixtures of LAC found in the ambient sample. The fundamental problem with the LAC-OC split in ambient samples is that there is not an objective definition to distinguish between the two analytes. Without such a definition, there is no way this distinction can be traced to fundamental principles. We are left with only the ostensive definition that the desired distinction is just what the method delivers. Imperfections of the method, however, do not change the need for rigorous interpretation of the existing data set, which represents a substantial investment of time and capital.

Because thermal techniques only yield an estimate of the carbon component of an organic aerosol, the evolved carbon must be multiplied by a scaling factor, $R_{\mathrm{oc}}$, to develop an estimate of OC mass. Hand et al. (2019) have shown that $R_{\mathrm{Oc}}$ values, on the average, have increased from 2005 to 2016 in the continental United States (CONUS). In this paper an explanation is offered for this increase, based on misapportionment of EC1 to OC and LAC. Chow et al. (2018) do suggest that some light-absorbing OC may be apportioned to LAC in a small number of samples. It is suggested that, in general, OP is a bifurcated mixture of OC and LAC, or low-R-type material, and that as the fraction of OP that is LAC has decreased over time, the resulting $R_{\mathrm{Oc}}$ has on the average increased with time. A first-order model is presented that allows for an estimation of the fraction of LAC or OC in OP.

\section{Estimating Organic Mass to OC Ratios}

Carbon aerosols are chemically complex, with organic to carbon mass ratios $\left(R_{\mathrm{oc}}\right)$ that vary from values near 1 for aerosols containing mostly BC to as high as 3.75 for oxalic acid (El-Zanan et al., 2005; Nicolosi et al., 2018). LAC is usually present in the atmosphere as an internal mixture of "chained" carbon molecules embedded with secondarily formed organic molecules, sulfur, salts such as sodium, and dust. The mass of a volume of organic aerosols can be expressed as

$$
O M C=\sum_{j} R_{j} O C_{j}
$$

where $\mathrm{OMC}$ is the aggregate mass concentration of ambient $\mathrm{OC}$ aerosols and $\mathrm{R}_{\mathrm{j}}$ is the ratio of the mass of the $j$ th organic species to its carbon mass, $\mathrm{OMC}_{\mathrm{j}} / \mathrm{OC}_{\mathrm{j}}$. Typically, it is assumed that 
Table 1

Carbon Mass Concentration Variables and Associated R Values Derived From Reported Thermal-Optical Analysis Carbon Concentrations OC1, OC2, OC3, OC4, OP, and $L A C$

\begin{tabular}{|c|c|c|c|}
\hline Carbon variable & Derived variable & $R$ value for each of the carbon mass variables & Comments \\
\hline $\mathrm{OL}$ & $\mathrm{OL}=\mathrm{OC} 1+\mathrm{OC} 2+\mathrm{OC} 3+\mathrm{OC} 4$ & $R_{\mathrm{Ol}}=\mathrm{OML} / \mathrm{OL}$ & OML is the total mass of OL \\
\hline OP & $\mathrm{OP}=\mathrm{EC} 1+\mathrm{EC} 2+\mathrm{EC} 3-\mathrm{ECR}$ & $R_{\mathrm{op}}=\mathrm{OMP} / \mathrm{OP}$ & OMP is the total mass of OP \\
\hline LAC & $\mathrm{LAC}=\mathrm{ECR}$ & $R_{\mathrm{LAC}}=\mathrm{LACM} / \mathrm{LAC}$ & $\begin{array}{l}\text { LACM } \approx \mathrm{LAC} \text {, so } \mathrm{R}_{\mathrm{LAC}} \text { is typically } \\
\text { assumed to be approximately } 1\end{array}$ \\
\hline $\mathrm{OC}$ & $\mathrm{OC}=\mathrm{OL}+\mathrm{OP}$ & $R_{\mathrm{OC}}=\mathrm{OMC} / \mathrm{OC}$ & \\
\hline TC & $\mathrm{TC}=\mathrm{OC}+\mathrm{LAC}$ & $R_{\mathrm{tc}}=\mathrm{TMC} / \mathrm{TC}$ & \\
\hline $\mathrm{OC}_{\mathrm{op}}$ & $\mathrm{OC}_{\mathrm{op}}=\mathrm{fOP}$ & $R_{\mathrm{Oo}}=\mathrm{OMC}_{\mathrm{op}} / \mathrm{fOP}$ & $R$ factor for the $\mathrm{OC}$ in $\mathrm{OP}$ \\
\hline $\mathrm{LAC}_{\text {op }}$ & $\mathrm{LAC}_{\mathrm{op}}=(1-f) \mathrm{OP}$ & $R_{\mathrm{LAC} \_\mathrm{OP}} \approx 1.0$ & $R$ factor for the LAC in OP \\
\hline LRC & \multirow{2}{*}{\multicolumn{3}{|c|}{ Refers to low organic to carbon mass ratios with 1 being the limiting lowest $R$ value }} \\
\hline HRC & & & \\
\hline
\end{tabular}

Note. ECR is the reported fraction of EC1 that is interpreted as light absorbing carbon, $f$ is the fraction of OP that is organic carbon, and (1- $f$ ) is the fraction of OP that is LAC.

$$
\sum_{j} R_{j} O C_{j} \approx R_{o c} O C
$$

where $R_{\mathrm{oc}}$ is the average $\mathrm{OMC} / \mathrm{OC}$ ratio of ambient organic aerosols and $O C=\sum_{j} O C_{j}$. Table 1 summarizes the variables used in the following analysis.

Total atmospheric mass concentrations can be estimated by summing the mass concentrations of individual aerosol species of particles less than $2.5 \mu \mathrm{m}$, usually referred to as fine mass $\left(\mathrm{PM}_{2.5}\right)$ concentrations:

$$
\mathrm{PM}_{2.5}=a_{1} \mathrm{SO}_{4}+a_{2} \mathrm{NO}_{3}+a_{3} \mathrm{OC}+L A C+S S+D U S T,
$$

where $\mathrm{PM}_{2.5}$ is reconstructed fine mass; $\mathrm{SO}_{4}, \mathrm{NO}_{3}, \mathrm{OC}$, LAC, and $\mathrm{SS}$ are the measured chemical species; and the corresponding $a_{\mathrm{i}}$ values are the factors applied to scale the measured species mass up to an assumed molecular form (Malm et al., 1994). For instance, if it is assumed that sulfates are in the form of ammonium sulfate, then $a_{1}=1.375$, and $a_{3}$ is interpreted as $R_{\mathrm{oc}}$. DUST is estimated from measurements of elements assumed to contribute to dust mass concentrations, and sea salt (SS) is estimated from measurements of the chloride ion.

\subsection{Range of $R_{\mathrm{oc}}$ Values}

There are several methods by which estimates of $R_{\mathrm{oc}}$ have been developed (Aiken et al., 2008; Bae, Demerjian, \& Schwab, 2006; Bae, Schauer, \& Turner, 2006; Chan et al., 2010; Gilardoni et al., 2007; Kiss et al., 2002; Liu et al., 2009; Lowenthal \& Kumar, 2006; Reff et al., 2007; Russell, 2003; Sun et al., 2009; Turpin \& Lim, 2001; Yu et al., 2005). Probably the most straightforward method of estimating $R_{\mathrm{oc}}$ is a simple mass balance (MB) calculation where all aerosol species other than OMC (Other) are measured along with gravimetric particulate mass (PM) and OC. Then, the difference between PM and Other is OMC and $R_{\mathrm{oc}}=(\mathrm{PM}-$ Other $) / \mathrm{OC}$ (El-Zanan et al., 2005).

Another approach is to solvent-extract organic molecules from aerosol collected on an appropriate substrate, dry and weigh the residue, and then determine the carbon content by some analytic procedure such as TOR (El-Zanan et al., 2005; Turpin \& Lim, 2001). The ratio of these two variables is an estimate of the $R_{\mathrm{oc}}$ of the extracted material. A similar approach is to carry out an elemental analysis of the carbon extracts to determine their mass and thereby their $R_{\mathrm{oc}}$ factor (Kiss et al., 2002). Still, another approach is to develop $R$ factors for specific particle-phase compounds such as dicarboxylic acid and then mass-weight these factors to measured compounds in an aerosol collected in the ambient atmosphere (Kiss et al., 2002).

Aiken et al. (2008) use aerosol mass spectrometry (AMS) to measure all the organic fragments and develop an estimate of $R_{\mathrm{oc}}$ from the measured chemical composition of those fragments. A final approach is to develop a regression model where PM is the dependent variable and each of the aerosol species, including $\mathrm{OC}$, are the independent variables as indicated in equation (3). The regression coefficient associated with OC is then interpreted as the $R_{\mathrm{oc}}$ factor. 
General patterns in the $R_{\mathrm{oc}}$ are seen with typically lower values in less-aged aerosols found in urban centers compared to rural areas and generally lower $R_{\mathrm{oc}}$ values in the winter months compared to the summer months (Malm et al., 2011). In a 13-month study in Pittsburgh, Pennsylvania, Polidori et al. (2008) analyzed the organic composition of extracts from $\mathrm{PM}_{2.5}$ samples and estimated the annual average $R_{\mathrm{oc}}$ value to be between 1.9 and 2.1, with somewhat higher ratios in the winter and summer compared to spring and fall.

Lowenthal et al. $(2009,2015)$, using winter and summer rural data sets, reported $R_{\mathrm{oc}}$ factors of 2.4 and 1.9 for water-soluble and dichloromethane extracts, respectively. Using a similar method at a remote site in the Rocky Mountains, Hallar et al. (2013) estimated the $R_{\mathrm{oc}}$ for water-soluble organics to be 2.04 during summer months. Lowenthal et al. (2015) and Polidori et al. (2008) suggest a seasonal dependence in the $R_{\mathrm{oc}}$ values. Other authors have also reported some seasonal dependence (El-Zanan et al., 2009; Malm et al., 2011; Polidori et al., 2008).

El-Zanan et al. (2009) used the MB approach on data collected in Atlanta, Georgia, in 1998-1999 and found an average $R_{\mathrm{oc}}$ of $2.16 \pm 0.43$, which matched the value of $2.17 \pm 0.17$ derived from solvent extracts. They also found a strong seasonal dependence, with average $R_{\mathrm{oc}}$ values of 1.77 in December to 2.39 in July. Bae, Schauer, and Turner (2006) used MB for a data set collected in St. Louis and estimated $R_{\mathrm{oc}}$ to be $1.95 \pm$ 0.17 in the summer and 1.77 0.13 in winter. However, Bae, Demerjian, and Schwab (2006), using MB for rural and urban New York data sets, reported a small seasonal dependence of $R_{\mathrm{oc}}$ for the rural site, with the warm season having a $R_{\mathrm{oc}}$ of 2.1, whereas the urban site did not have a seasonal dependence but did have lower $R_{\mathrm{oc}}$ factors of 1.3-1.6.

Fourier-transform infrared spectroscopy (FTIR) can be used to evaluate the functional groups of OMC collected on Teflon filters from which OMC and OC concentrations can be reconstructed (Russell et al., 2011). Russell et al. (2009) used this method to analyze filter samples from the Texas Air Quality Study and Gulf of Mexico Atmospheric Composition and Climate Study and found an average $R_{\mathrm{oc}}$ of $1.8 \pm 0.14$. Ruthenburg et al. (2014) used FTIR analysis on 1 year of IMPROVE Teflon filters at seven sites to estimate OMC. From this work they found that the median $R_{\mathrm{oc}}$ was 1.69, with the 10th and 90th percentiles being 1.46 and 2.01, respectively. The one urban site, Phoenix, Arizona, had the lowest annual median value of 1.56. The lowest monthly median $R_{\mathrm{oc}}$ ratio also tended to occur in winter months. These FTIR results are more in line with the linear regression analyses than those using solvent extracts and MB.

$R_{\mathrm{oc}}$ factors derived from extracts and MB tend to be higher than that suggested by Malm and Hand (2007). However, other national analyses based on linear regression and modeling methods are more in line with those of Malm and Hand (2007). Simon et al. (2011) conducted a regression analysis of IMPROVE data from 186 sites for the years 2002-2008. They found that the 5th to 95th percentile of annual average $R_{\mathrm{oc}}$ across sites was 1.10 to 2.06 and had a median value of 1.66. However, they also found larger seasonal differences, with a median $R_{\mathrm{oc}}$ of 1.81 in the third quarter of the year compared to 1.39 in the first quarter. Spatial patterns were also evident, typically with higher values at eastern sites than western sites, particularly in the winter months. These results are consistent with $R_{\mathrm{oc}}$ values derived from a modeling study by Simon and Bhave (2012). Malm et al. (2011) also used a regression method on rural IMPROVE and urban and suburban Chemical Speciation Network data and found higher $R_{\mathrm{oc}}$ values during the summer than winter for both rural and urban settings. The lowest $R_{\mathrm{oc}}$ values occurred at the urban sites, ranging from about 1.3 (winter) to 1.6 (summer). Suburban and rural sites had similar $R_{\mathrm{Oc}}$ values, ranging from 1.4 (winter) to 1.7-1.8 (summer).

The MB and solvent extraction approaches generally yield higher $R_{\mathrm{oc}}$ ratios than regression models using TOR-derived OC and LAC concentrations. The possibility exists that the MB and extraction approaches are sensitive to only the organic material on the filter, while the regression model is sensitive to whatever OC material that is defined by the TOR analysis scheme. Possibly some LAC-type material is inadvertently assigned to the OC fraction, resulting in regression models yielding lower $R_{\mathrm{Oc}}$ factors. This possibility will be explored next.

\section{Concentration Trends in OC, OP, and LAC}

Hand et al. (2019) show that $R_{\mathrm{oc}}$, the OMC/OC ratio, has increased over time at a statistically significant rate across most of CONUS. An exploration of temporal trends in OC, OP, and LAC as well as concurrent trends in these variables will give some insight into the cause of the increase in $R_{\mathrm{oc}}$ over time. 


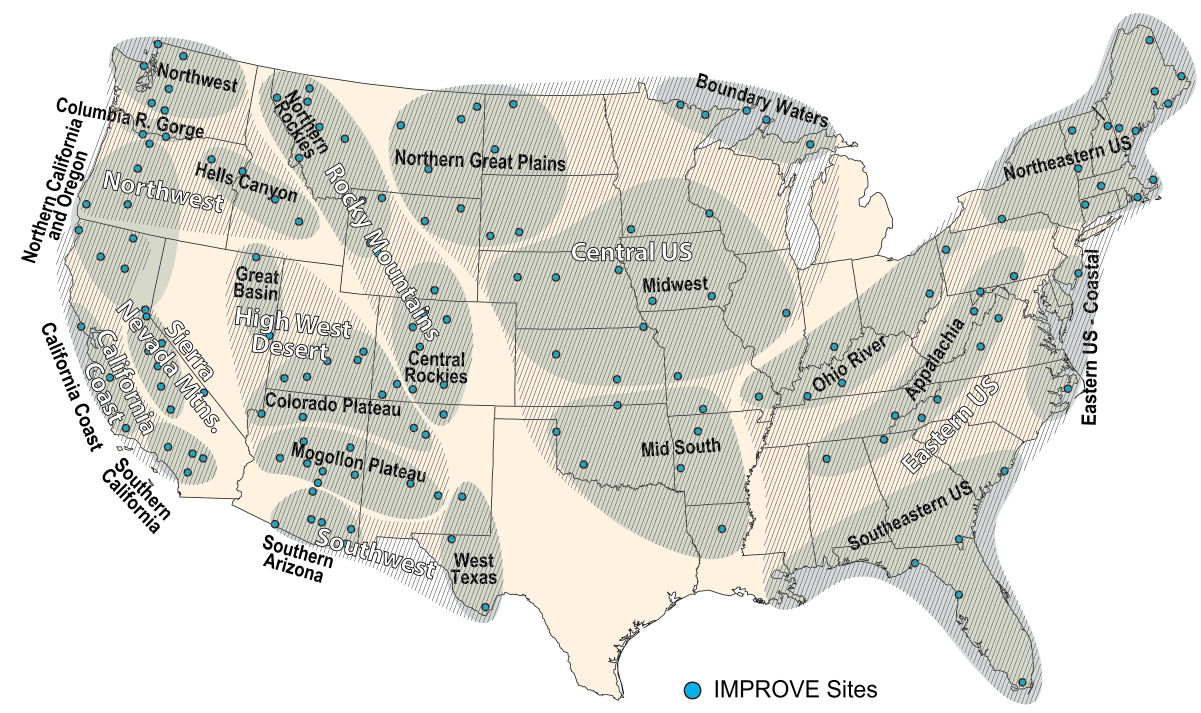

Figure 2. Locations of IMPROVE monitoring sites as well as the grouping of the sites into regions.

Although there are currently 157 monitoring sites in IMPROVE, only 150 nonurban sites with the most complete records, shown in Figure 2, will be used for the analysis presented in this paper. The data from these sites are available on the IMPROVE website (at http://vista.cira.colostate.edu/improve/).

The 150 monitoring sites used in this analysis and operating in the IMPROVE network during 2006-2017 were grouped into 23 regions (Hand et al., 2012; Malm et al., 2002) and for the purposes of this paper into eight larger regions, which are shown as hatched areas. The regions were selected based upon topography and the expected spatial extent of fine aerosols. The groupings were further refined by examining the individual monthly aerosol composition patterns for each site within a region. Additionally, data corresponding to $\mathrm{OC}$ greater than $10.0 \mu \mathrm{g} / \mathrm{m}^{3}$ were removed from the analysis to minimize extreme concentrations associated with fire events affecting averages and regression analysis.

The spatial and temporal trends of OC and LAC across CONUS are presented in some detail by Hand et al. (2013) and Malm et al. (2011, 2017). The following discussion highlights average values of OC, OP, and LAC

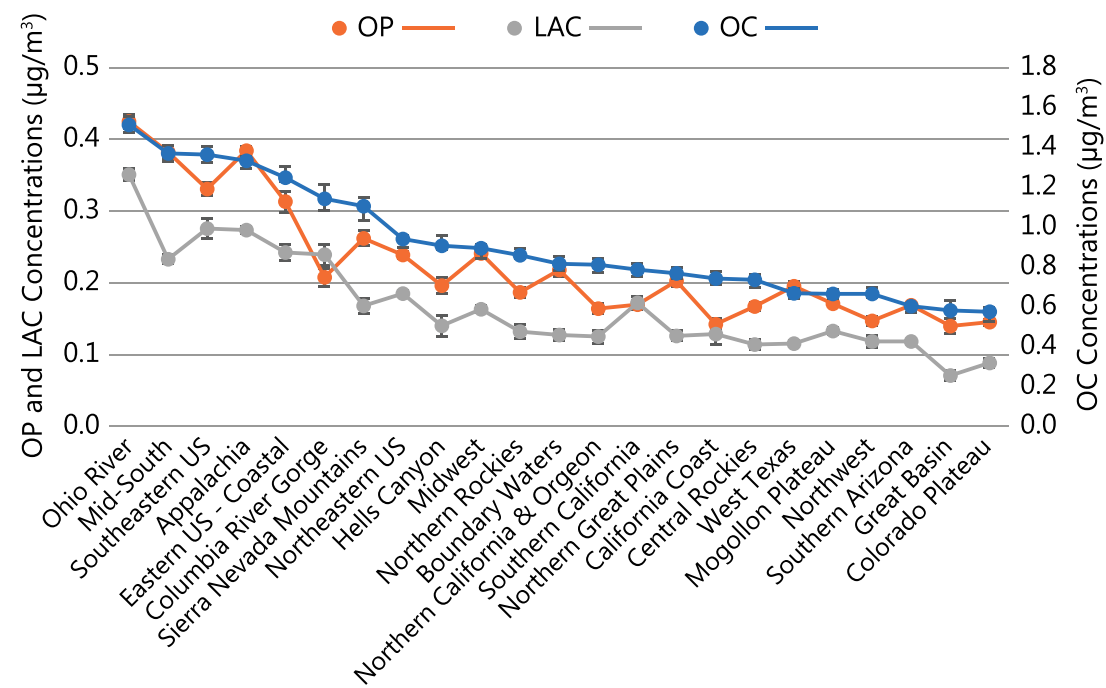

Figure 3. Average concentrations and standard errors for 2006-2017 of OC, OP, and LAC for each of the regions shown in Figure 2. 


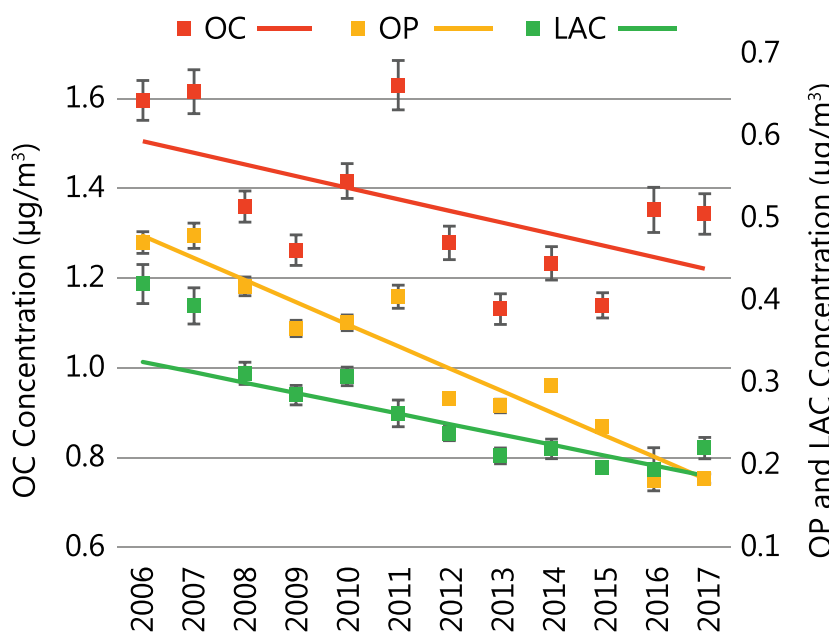

Figure 4. Temporal trends in yearly average values of OC, OP, and LAC for the Southeast region. Error bars are the standard error for each 1-year average. from 2006 and 2017. Only those years were used because of instrumentation changes and problems in prior years (http://vista.cira. colostate.edu/improve). There also was an instrumentation change starting in 2016.

Figure 3 shows the 2006-2017 average concentrations of OC, OP, and LAC. The left-hand scale corresponds to OP and LAC concentrations while the right-hand axis represents OC concentrations. Average OC concentration in the East and West are about 1.3 and $0.6 \mu \mathrm{g} / \mathrm{m}^{3}$, respectively. Average concentrations of OP vary from 0.4 to 0.3 $\mu \mathrm{g} / \mathrm{m}^{3}$ in the East and are about $0.18 \mu \mathrm{g} / \mathrm{m}^{3}$ for most of the western CONUS. LAC concentrations are about $0.25 \mu \mathrm{g} / \mathrm{m}^{3}$ in the East and $0.1 \mu \mathrm{g} / \mathrm{m}^{3}$ in the West. Error bars are the standard errors for each of the average values. Uncertainty associated with measurement precision for each average value is less than $1 \%$.

Figure 4 shows changes in yearly average OC, OP, and LAC concentrations for the years 2006-2017 for the Southeast region, which are also typical for all regions shown in Figure 2. The left-hand axis shows concentrations for $\mathrm{OC}$, while the right-hand axis represents concentrations for OP and LAC. The uncertainty bars represent the standard error of each data point. Measurement uncertainty associated with the precision of each measurement is less than $1 \%$. A Theil regression line is also shown for each of the variables. The regression line for OC is not significant at the $10 \%$ level, but the trends for OP and LAC are.

On the average the decrease in OP concentrations over the 12-year period from 2006 to 2017 is about $0.025 \pm$ $0.003 \mu \mathrm{g} / \mathrm{m}^{3} /$ year, while for LAC it is $0.01 \pm 0.001 \mu \mathrm{g} / \mathrm{m}^{3} /$ year. OC concentrations decrease on the average about the same as OP concentrations. This corresponds to about a 20\%, 60\%, and 45\% concentration reductions for OC, OP, and LAC, respectively. Notice that nearly all the reduction in OC is due to decreases in the fraction of $\mathrm{OC}$ that is OP.

Figure 5 summarizes the trends and their uncertainties for each of the 23 regions shown in Figure 3 . The height of each bar is the temporal trend of an aerosol species in units of $\mu \mathrm{g} / \mathrm{m}^{3} /$ year, and the uncertainty bars correspond to the standard error of the regression coefficient representing the trend. A positive bar implies a

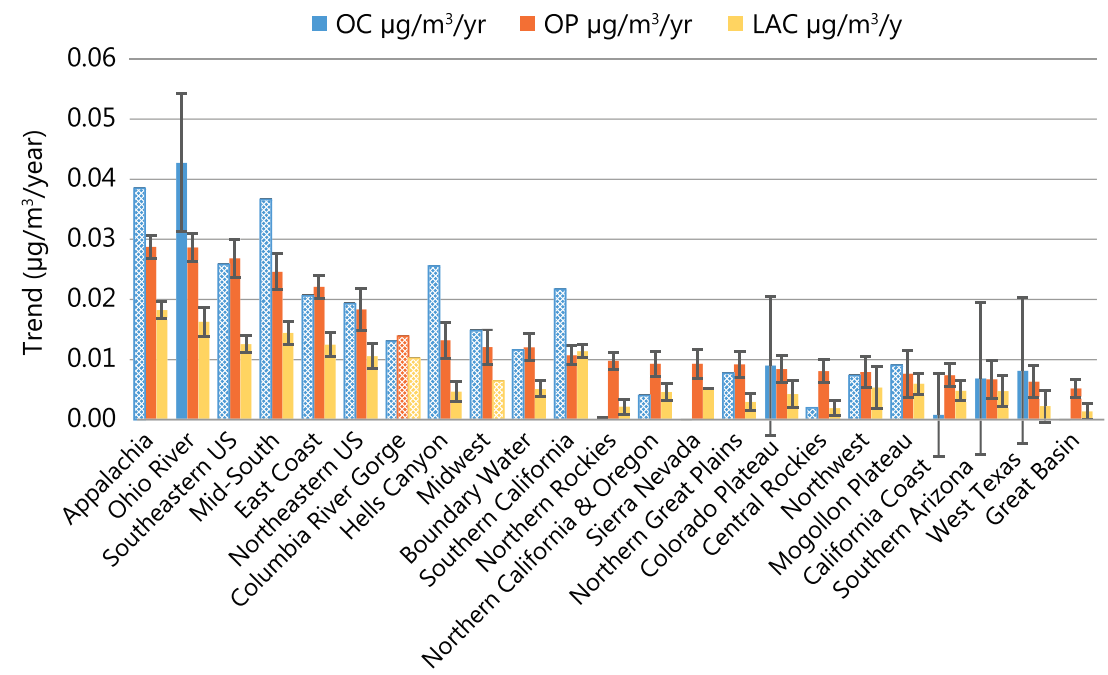

Figure 5. Temporal trends expressed as decreases in yearly concentrations for OC, OP, and LAC for each region of CONUS shown in Figure 3. Solid bars indicate trends that are statistically significant at least at the $10 \%$ level, while a hatched bar correspond to trends that are not statistically significant at the $10 \%$ level. Uncertainty bars are only shown for trends that are significant at the $10 \%$ level or better. 


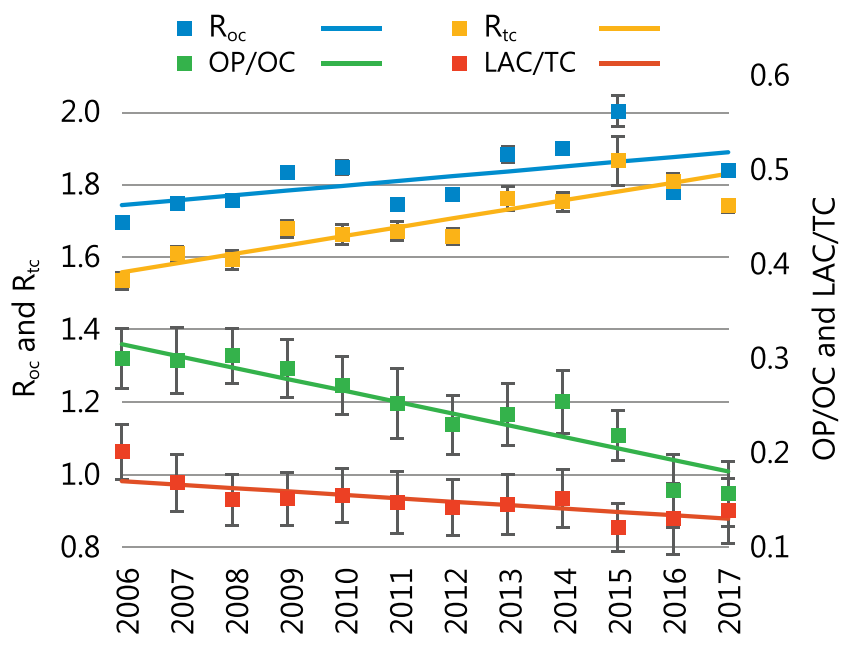

Figure 6. Yearly average temporal trends for $R_{\mathrm{tc}}, R_{\mathrm{Oc}}, \mathrm{OP} / \mathrm{OC}$, and LAC/TC for the Southeast region.

downward trend in concentration over time; conversely, a negative bar implies an upward trend. Each species is represented by a color; a hatched color indicates that the trend was not significant at the $10 \%$ level. For instance, in the Columbia River Gorge, none of the trends for any species are significant, and only four of the OC trends are significant. Conversely, nearly all the trends for OP and LAC are significant at the $10 \%$ level.

Most OC trends are not significant; however, on the average from 2006 to 2017, OC has decreased by about 20\% across all of CONUS. OP downward trends are significant in most regions of CONUS and on the average correspond to about a $45 \%$ and $35 \%$ change in the East and West, respectively. Trends in LAC are similar to OP with about a $40 \%$ decrease in the East and $20 \%$ in the West.

\subsection{Concurrent Trends in $R_{\mathrm{oc}}$ and OP/OC}

Equation (3) can be modified slightly so that the $a_{\mathrm{i}}$ coefficients can be determined using a regression model. For instance,

$$
P M_{2.5, i}=a_{1} S_{4, i}+a_{2} N_{3, i}+a_{3} O C_{i}+a_{4}\left(D U S T_{i}+S S_{i}+L A C_{i}\right)
$$

or

$$
P M_{2.5, i}=a_{1} S O_{4, i}+a_{2} N_{3, i}+a_{3} T C_{i}+a_{4 i}\left(D U S T_{i}+S S_{i}\right),
$$

where $P M_{2.5}, i$ is gravimetric mass and TC is total carbon (TC $\left.=\mathrm{OC}+\mathrm{LAC}\right)$. The subscript $i$ refers to the $i$ th sample. In the case of equation (4), $a_{3}$ is interpreted as a weighted average $R_{\mathrm{oc}}$ value, while in equation (5) it is the average $R_{\mathrm{tc}}$ factor associated with total carbon mass (TMC $=R_{\mathrm{tc}} \mathrm{TC}$ ).

An ordinary least squares (OLS) regression was used to solve equations (4) and (5) assuming an intercept of zero. The data sets were formed by combining all observations by season or year from each site in a region into one large data set that typically resulted in over 1,000 observations.

Figure 6 is a temporal plot of yearly average $R_{\mathrm{oc}}, R_{\mathrm{tc}}$, and the ratios of LAC to TC (LAC/TC) and OP to OC (OP/OC) along with Theil regression lines for the Southeast region shown in Figure 2. The downward trends in LAC/TC $(-0.004 \pm 0.001 /$ year $)$ and $\mathrm{OP} / \mathrm{OC}(-0.013 \pm 0.002 /$ year $)$ and upward trends in $R_{\mathrm{oc}}(0.013 \pm$ $0.006 /$ year $)$ and $R_{\mathrm{tc}}(0.025 \pm 0.0004 /$ year $)$ are significant at least at the $10 \%$ level. The standard error for $R_{\mathrm{Oc}}, R_{\mathrm{tc}}$, and the LAC/TC and OP/OC ratios are also shown. OC, OP, LAC, and TC all are decreasing over time; however, the decreasing trend of the ratio of OP/OC and LAC/TC implies that OP and LAC are decreasing faster than $\mathrm{OC}$ and TC.

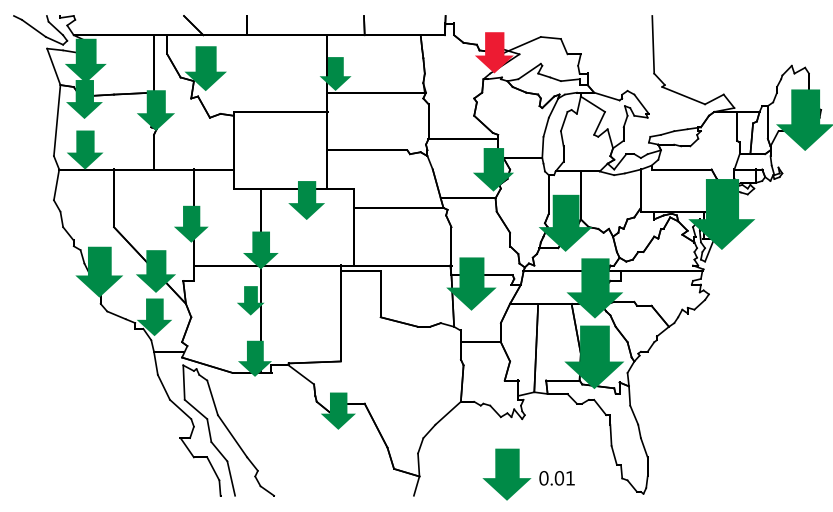

Figure 7. Yearly trends in OP/OC for the 23 IMPROVE regions, calculated using a Thiel regression analysis; green arrows represent a significance level of at least $10 \%$, while red arrows represent a significance level of less than $10 \%$.
$R_{\mathrm{tc}}$ is just the weighted average of the $R$ values for OC and LAC. As the fraction of LAC, which has an $R$ factor near 1, in TC decreases over time relative to OC, the remaining carbon aerosol consists of higher- $R$ carbon (HRC), hence the increase in $R_{\mathrm{tc}}$.

A similar argument can be made for the relative trends in OP/OC and $R_{\mathrm{oc}}$. As the fraction of OP in OC has declined, $R_{\mathrm{oc}}$ has increased. Either OP is a mixture of carbon with a lower $R$ (defined as $R_{\mathrm{op}}$ ) than $R_{\mathrm{Oc}}$, and as the OP in OC decreases, the weighted average $R$ value $\left(R_{\mathrm{Oc}}\right)$ of the various $\mathrm{OC}_{\mathrm{i}}$ molecules in $\mathrm{OL}+\mathrm{OP}$, as defined by equation (2), increases, or the $R$ for OL (organic carbon in OC other than OP, $R_{\mathrm{ol}}$ ) is increasing because the chemical composition of atmospheric carbon is changing, or both. It will be shown below that $R_{\mathrm{ol}}$ is likely not changing over time.

Figure 7 is a plot showing that from 2006 to 2017, the decreasing trend in the OP/OC ratio occurs over the entire United States at a rate 

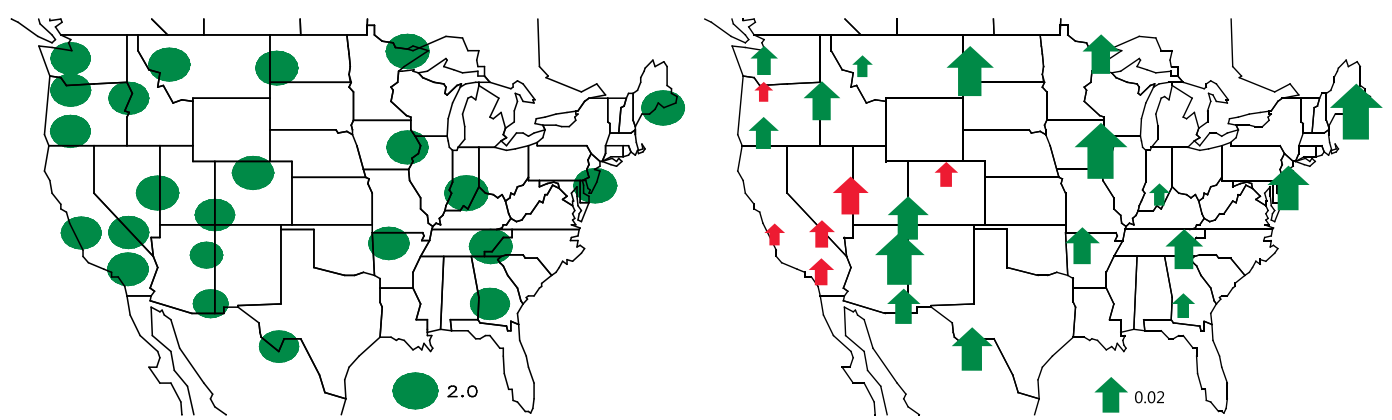

Figure 8. (a) $R_{\mathrm{Oc}}$ values for each of the 23 IMPROVE regions for 2006-2008. (b) Yearly trends in $R_{\mathrm{Oc}}$ for the 23 IMPROVE regions, calculated using a Thiel regression analysis; green arrows represent a significance level of at least $10 \%$, while red arrows represent a significance level of less than $10 \%$.

of -0.005 to $-0.01 /$ year. Green arrows represent a statistical significance of the temporal trend at least at the $10 \%$ level, while a red arrow indicates a lesser statistical significance. In the eastern United States, the OP/OC ratio decreases from about 0.3 in 2006 to 0.2 in 2017. The average CONUS OP/OC is $-0.26 \pm 0.05$, while the average trend in the ratio is $-0.0087 \pm 0.002$ /year, with trends in the eastern United States exceeding -0.012 / year.

Figure 8a shows $R_{\mathrm{oc}}$ for 2006-2008, while Figure 8b shows the rate of change of $R_{\mathrm{oc}}$ per year as the slope of the Theil regression line as shown in Figure 6, for each of the regions represented in Figure 2. Green triangles indicate a statistical significance greater than $10 \%$ while red triangles are less significant. The average temporal rate of increase in $R_{\mathrm{oc}}$ is $0.02 \pm 0.008$ /year. Most regions show a statistically significant trend of increasing $R_{\mathrm{oc}}$ except for six regions in the western United States.

As indicated above, it is of interest to explore changes in the $R$ factor of OC other than OP defined as $\mathrm{OL}=\mathrm{OC}-\mathrm{OP}$. The following equation was formed and solved using an OLS regression:

$$
P M_{2.5}, i=a_{1} S_{4 i}+a_{2} N_{3 i}+a_{3} O L i+a_{4}(D U S T+S S+L A C+O P)_{i} .
$$

In this equation, $a_{3}$ is interpreted as the $R$ factor for $\mathrm{OL}\left(\mathrm{R}_{\mathrm{ol}}\right)$, and $i$ refers to the $i$ th observation.

Figure 9 is a temporal plot of $R_{\mathrm{ol}}, R_{\mathrm{oc}}$, and the difference between $R_{\mathrm{ol}}$ and $R_{\mathrm{oc}}\left(R_{\mathrm{ol}}-R_{\mathrm{oc}}\right)$ for the Southeast region of CONUS. As before, the standard errors for $R_{\mathrm{oc}}, R_{\mathrm{ol}}$, and $R_{\mathrm{ol}}-R_{\mathrm{oc}}$ are shown. The Theil-regression-derived slopes of the $R_{\mathrm{ol}}$ factors over time for the most part are not statistically significant but tend toward a constant value of between 2.0 and 2.2.

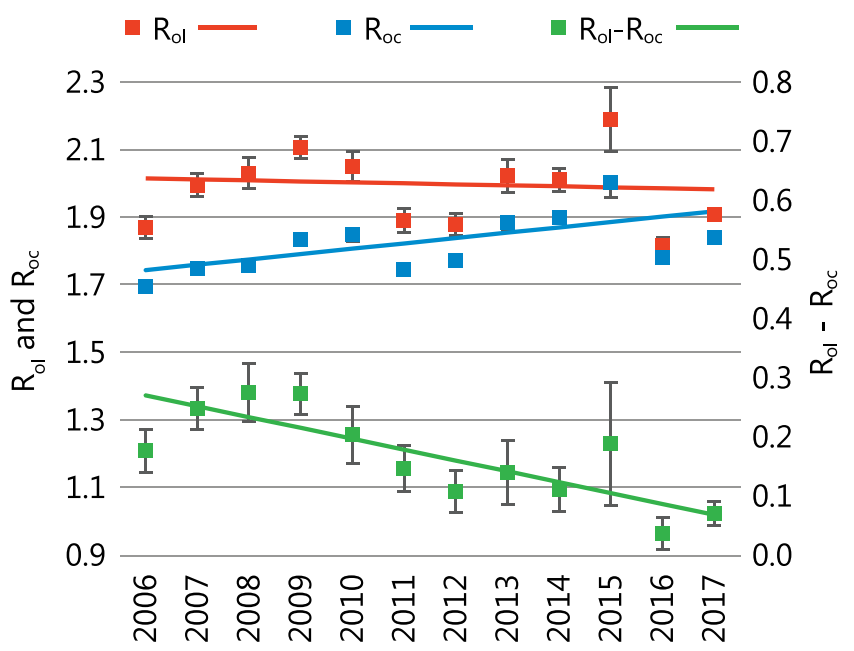

Figure 9. Yearly average temporal trends $R_{\mathrm{Ol}}$ and $R_{\mathrm{Oc}}$ and the difference $\left(R_{\mathrm{ol}}-R_{\mathrm{oc}}\right)$ for the Southeast region.
The average $R_{\mathrm{ol}}$ across all regions is $2.1 \pm 0.15$. On the other hand, the temporal trend in $R_{\mathrm{Oc}}$ across CONUS, as shown in Figure $7 \mathrm{~b}$, is increasing over time at a statistically significant rate of about $0.02 \pm 0.008$ /year. While the $R_{\mathrm{ol}}$ slope over time is generally not significant, the difference between $R_{\mathrm{ol}}$ and $R_{\mathrm{oc}}$ is. The difference between $R_{\mathrm{ol}}$ and $R_{\mathrm{oc}}$ is about 0.25 in the 2006-2009 time frame and decreases toward zero in 2017.

If $R_{\mathrm{ol}}$ has not changed over time, then two bounding assumptions concerning the composition of OP are that it is some uniform mixture of lower- $R$ carbon or that it is a bifurcated mixture of OC and LAC with an $R$ factor near 1 . Given that $R_{\mathrm{oc}}$ approaches $R_{\mathrm{ol}}$ as OP/OC decreases but before OP approaches zero suggests that $\mathrm{OP}$ is a mixture of OL-type molecules with an $R$ factor near that of OL and a LAC- or LRC-type molecule with an $R$ factor near 1 . Therefore, as LAC decreases relative to $\mathrm{OC}$ in OP over time, the $R$ value of OC approaches that of $R_{\mathrm{ol}}$, because $R_{\mathrm{oc}}$ is the mass-weighted average of the $R$ factor for OP $\left(R_{\mathrm{op}}\right)$ and $R_{\mathrm{ol}}$. 


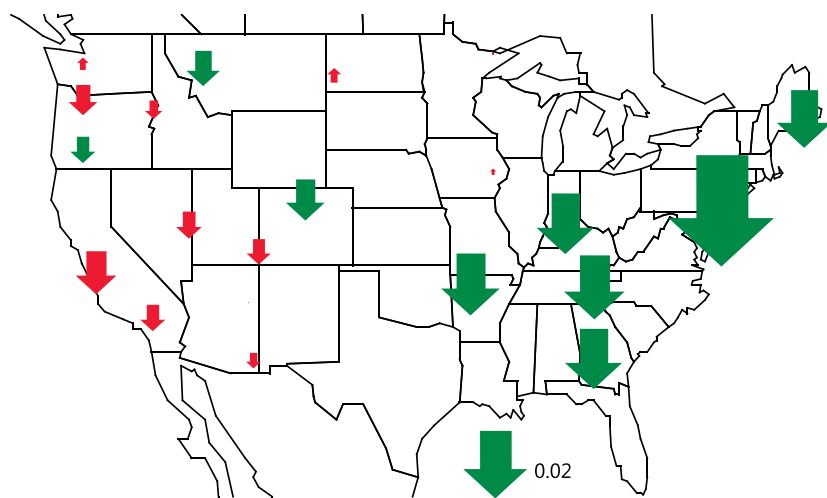

Figure 10. Yearly average temporal trends in $R_{\mathrm{Ol}}-R_{\mathrm{Oc}}$ for the 23 IMPROVE regions. Yearly trends were calculated using a Thiel regression analysis; green arrows represent a significance level of at least $10 \%$, while red arrows represent a significance level of less than $10 \%$.
Figure 10 shows the trend in yearly averaged $R_{\mathrm{ol}}-R_{\mathrm{oc}}$ values as the Thiel-derived slope of this average difference over time. As before, green arrows have a significance level of better than $10 \%$, while red arrows indicate a lesser significance. In the East, over a 12-year period, the difference between $R_{\mathrm{ol}}$ and $R_{\mathrm{oc}}$ decreases by about 0.2 , with $R_{\mathrm{oc}}$ going from about 1.8 to 2.0 , while in the West the $R_{\mathrm{ol}}-R_{\mathrm{oc}}$ decrease was 0.1 .

\section{Implications}

E1, as defined in Figure 1, is interpreted as a mixture of native LAC and OP, either of which may or may not have similar light-absorbing characteristics. Two of the assumptions inherent in the bifurcation of E1 into OC and LAC are that native LAC is elemental and maintains its absorptive characteristics as the filter is heated and that pyrolyzed carbon is elemental with the same absorption characteristics as native LAC.

Native LAC most likely is not EC or refractory carbon, and during pyrolysis, it too is converted from an organic light-absorbing molecule to something more akin to EC, resulting in a misapportionment of E1 into LAC and OC.

Given $R_{\mathrm{ol}}$ is approximately constant over time and $R_{\mathrm{oc}}$ approaching $R_{\mathrm{ol}}$ as OP/OC decreases but before $\mathrm{OP} / \mathrm{OC}$ is zero suggest that OP is a mixture of HRC material with an $R$ similar to OL and LRC similar to LAC with an $R$ near 1 . It is of interest to determine the fraction of OP that must be HRC-type carbon to achieve the observed $R_{\mathrm{Oc}}$ values. If it is assumed that OP is bifurcated into OC- and LAC-type molecules and the OC in OP has some average $R_{\mathrm{oo}}$ factor, then

$$
O M C=R_{o c}(O L+O P)=R_{o l} O L+f R_{o o} O P
$$

where $f$ is the fraction of OP that is OC with some $R$ factor $R_{\mathrm{Oo}}$ and $1-f$ is the fraction of OP that is LAC. Solving for $f$ yields

$$
f=\frac{O L\left(R_{o c}-R_{o l}\right)+O P\left(R_{o c}\right)}{O P\left(R_{o o}\right)} .
$$

If $R_{\mathrm{oo}} \approx R_{\mathrm{ol}}$ as suggested in Figure 9, then

$$
O M C=R_{o c}(O L+O P) \approx R_{o l}(O L+f O P) .
$$

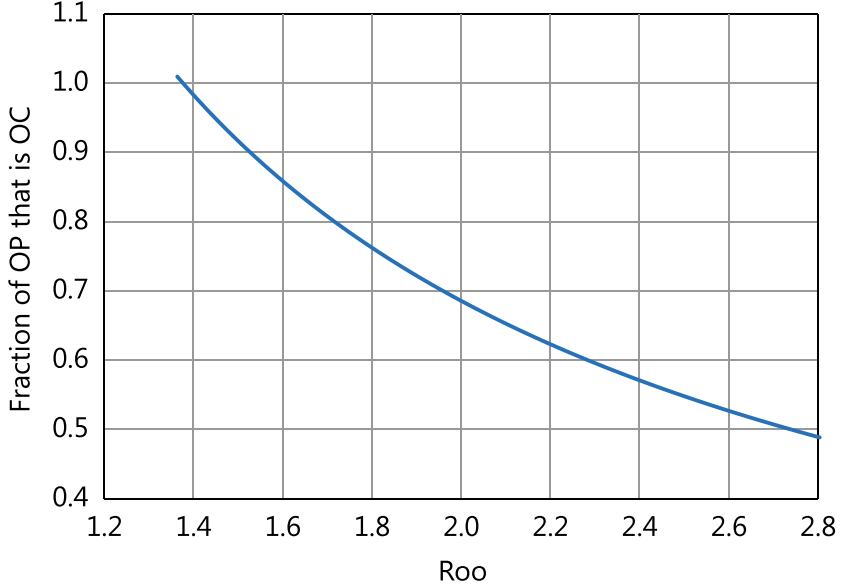

Figure 11. Fraction of $\mathrm{OP}$ that is $\mathrm{OC}$ as a function of the $\mathrm{R}$ factor of organic aerosol in OP for the eastern United States.
Again, solving for $f$ yields

$$
f \approx \frac{O L\left(R_{o c}-R_{o l}\right)+O P\left(R_{o c}\right)}{O P\left(R_{o l}\right)}
$$

Equation (10) allows for an estimate of the fraction of OP that is OL or LAC if $R_{\mathrm{oo}}=R_{\mathrm{ol}}$, while equation (8) allows for an exploration of the variability of that fraction as a function of varying the $R$ factor of the $\mathrm{OC}$ in $\mathrm{OP}(f \mathrm{OP})$.

Implicit in the structure of equation (7) or (9) is that OP is a bifurcated mixture of OC and LAC where OC has an $R$ factor of either $R_{\mathrm{Oc}}$ or $R_{\mathrm{Oo}}$, and LAC has an $R$ factor of 1 . It is possible to explore the effect of LAC being an LRC with some small $R_{\text {lac }}$ by adding a term, $R_{\text {lac }}(1-f) O P$, to equation (7) or (9) and again solving for $f$. The effect of assuming that LAC has some $R$ factor greater than 1 is to lower $f$, the fraction of OP that is OC-type molecules. 


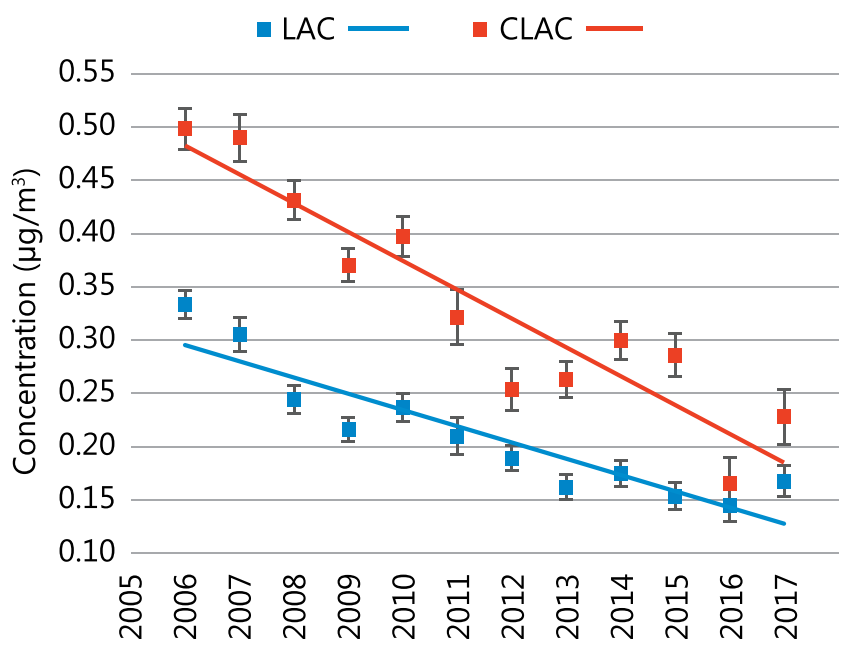

Figure 12. Temporal trends in measured LAC and CLAC for the eastern United States. Concentrations are in $\mu \mathrm{g} / \mathrm{m}^{3}$.
Figure 11 applies equation (8) to show the relationship between $R_{\mathrm{oo}}$ and the fraction of OP that is OC for the eastern U.S. region shown in Figure 2, averaged across years 2006-2017. The average $R_{\mathrm{ol}}$ factor for this data set is 2.23 , and $R_{\mathrm{oc}}$ is 1.99 . If the $R$ factor is the same for OL and the OC in OP $\left(R_{\mathrm{OO}}=R_{\mathrm{Ol}}\right)$, the fraction of OP that is OC or LAC is $61 \%$ and $39 \%$, respectively. If $R_{\mathrm{Oo}}$ is less than $R_{\mathrm{ol}}$, then the fraction of OP that is LAC is decreased and decreases to 0.0 for $R_{\mathrm{oo}}=1.37$.

\section{Correcting TOR-Reported OC and LAC for the $O C$ and $L A C$ in OP}

If $R_{\mathrm{oo}} \approx R_{\mathrm{ol}}$, as suggested by Figures 9 and 10, equation (10) allows for the estimation of the amount of OC or LAC contained in the OP mixture in the different regions of CONUS. The 23 regions shown in Figure 2 were further consolidated into eight regions, also outlined in Figure 2, with similar OC, OP, and LAC characteristics. They are Eastern U.S., Central U.S., Rocky Mountains, High West Desert, Northwest, Sierra Nevada Mtns., California Coast, and Southwest.

Data from the eight regions were used in equation (10) to estimate $f$, the average fraction of OC in OP for each year. The fraction of LAC, or more generally, LRC molecules in OP can also be estimated as $1-f$. Figure 12 shows the temporal trend in LAC and corrected LAC (CLAC) for the Eastern U.S. region. CLAC is the TOR-reported LAC plus the estimated LAC contained in the OP fraction. Uncertainty bars are shown for LAC and CLAC as standard errors of respective values.

Both TOR LAC and CLAC have statistically significant downward trends in all regions, with the CLAC trend always exceeding the LAC trend. The trends for the Eastern U.S. region are about 3\% and 1.5\% per year for the CLAC and LAC levels, respectively.

The average fraction of OP that is LAC, $1-f$, for the eight regions averaged over 2006-2017 as well as the standard error of those estimates are shown in Figure 13. On the average, within the uncertainty of estimated values, the fraction of LAC in OP across CONUS is between $30 \%$ and $40 \%$. The estimated $1-\mathrm{f}$ value for the Eastern U.S. region is highest at $42 \%$ and has the least uncertainty at about $\pm 1 \%$. Generally, the fraction of LAC in OP has decreased over the 2006-2017 time frame by about 25\%, except in the Central United States, Northwest, and Southwest regions where it has remained constant. The average fraction of OP that is LAC over the entire CONUS is $34 \pm 5 \%$.

Figure 14 shows the seasonal CONUS-wide average fraction of OP that is LAC $(1-f)$. Seasons are December, January, and February for winter and so forth. Also shown is the standard deviation for each of the seasonal averages. Even though within one standard deviation there is significant overlap of $1-f$ between seasons,

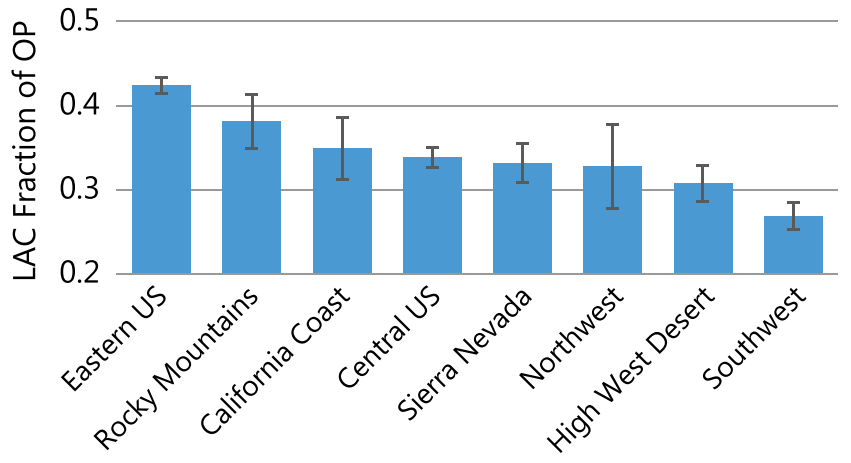

Figure 13. Average fraction and standard error of the OP that is LAC for 2006-2017. there does appear to be seasonal variability, with the summer season having an average value of about 0.35 and winter about 0.23 .

The average 2006-2017 difference between LAC and CLAC and OC and $\mathrm{COC}$ for the various regions of CONUS is summarized in Figure 15 as well as the percent difference between the uncorrected and corrected values. On an absolute basis, the largest correction of either LAC or OC occurs in the Eastern U.S. region, because ambient concentrations are highest in this region; however, the concentration differences on a percentage basis are about the same across all of CONUS, except for the Sierra Nevada region, which has a larger increase of LAC and a commensurate decrease in OC. The average CONUS-wide increase of CLAC over LAC is $56 \pm 13 \%$, while the concurrent decrease in $\mathrm{OC}$ is $10 \pm 4 \%$. The percent increase of decrease is calculated relative to the original value. 


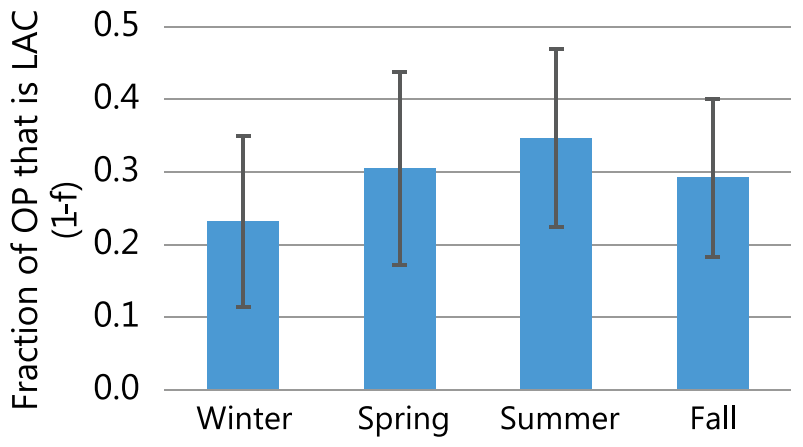

Figure 14. Average seasonal fraction of OP that is LAC, averaged across all monitoring sites in CONUS for 2008-2017.

\section{An Alternative Estimation of LAC Concentrations}

Chow et al. (2004) put forth an alternative method for estimating LAC and OP from the optical transmittance measurements (Figure 1) that is independent of the TOR-derived LAC and OP. Specifically, they assumed that

$$
\left[\text { Carbon after } \mathrm{O}_{2}\right]=[L A C]+[O P]=\frac{\tau_{a, L A C o}}{M A E_{L A C_{o}}}+\frac{\tau_{a, O P o}}{M A E_{O P_{o}}},
$$

where $[L A C]$ and $[O P]$ are the mass concentrations of light absorbing and charred carbon as determined by TOR; $L A C_{\mathrm{o}}$ and $O P_{\mathrm{o}}$ refer to optically derived LAC and OP; $M A E_{L A C_{o}}$ and $M A E_{O P_{o}}$ are the mass absorption efficiencies (MAE) of $\mathrm{LAC}_{\mathrm{o}}$ and $\mathrm{OP}_{\mathrm{o}}$, respectively; and $\tau_{a, L A C o}$ and $\tau_{a, O P o}$ are the attenuation of light or optical depth due to $\left[L A C_{\mathrm{o}}\right]$ and $\left[O P_{\mathrm{o}}\right]$, respectively.

[LAC] and [OP] are measured in the thermal analysis, and $\tau_{a, L A C o}$ and $\tau_{a, O P o}$ are estimated from the measured transmittance initial $\left(T_{\mathrm{i}}\right)$, final $\left(T_{\mathrm{f}}\right)$, and minimum $\left(T_{\mathrm{m}}\right)$ values using

$$
\tau_{a, L A C o}=-\ln \left(\frac{T_{i}}{T_{f}}\right)
$$

and

$$
\tau_{a, O P o}=-\ln \left(\frac{T_{m}}{T_{i}}\right)
$$

The MAEs are unknown. However, under the assumption that the MAEs are reasonably constant, Chow et al. (2004) used linear regression to estimate the absorption efficiencies and thus the $\left[L A C_{\mathrm{o}}\right]$ and $\left[O P_{\mathrm{o}}\right]$ concentrations on a subset of IMPROVE samples where the $T_{\mathrm{m}}$ was detectable and there were no early OC/EC splits. This resulted in LAC concentrations greater than those estimated using TOT and generally greater than or equal to LAC from TOR.

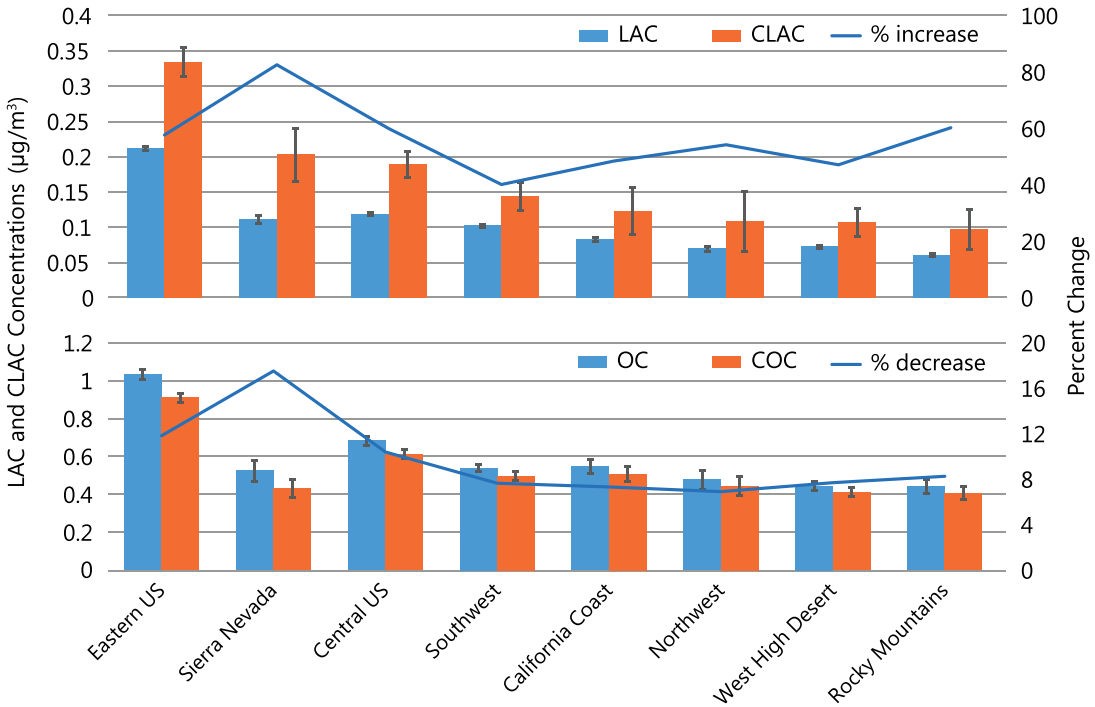

Figure 15. (a) Average 2006-2017 LAC and CLAC as well as the percent difference between CLAC and LAC for the eight regions. Error bars are the standard error of each variable. (b) Average 2006-2017 OC and COC as well as the percent difference between $\mathrm{COC}$ and $\mathrm{OC}$ for the eight regions. Error bars are the standard error of each variable. 


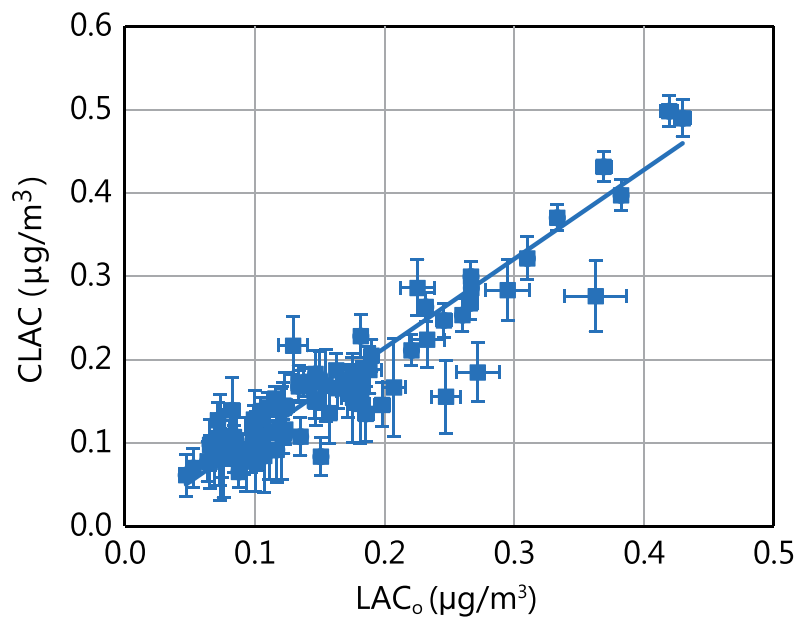

Figure 16. LAC derived from the optical thickness plotted against CLAC along with corresponding standard error values.
In this work, a similar regression analysis was conducted using IMPROVE data for each year and region to estimate the regional annual average $L A C_{\mathrm{o}}$. These optical-derived $L A C_{\mathrm{o}}$ concentrations are compared to the corresponding CLAC concentrations in Figure 16. As shown, the agreement between the two variables is surprisingly good, with an OLS slope of $1.01 \pm 0.04$ and an $R^{2}=0.83$, further suggesting that reported LAC concentrations obtained using TOR are an underestimate of true concentrations by about $60 \%$.

Two independent analysis techniques imply that reported $\mathrm{OC}$ and LAC derived using the current TOR protocol in the IMPROVE monitoring program overestimate OC by $10 \%$ and underestimate LAC by about $60 \%$. The first argues, based on temporal trends in $R_{\mathrm{oc}}$ and concentrations of $\mathrm{OC}, \mathrm{OP}$, and LAC, that $\mathrm{OP}$ is a bifurcated mixture of OC similar to OL- and LAC-type molecules with the fraction of OP that is LAC being about 35\%. The second independent analysis technique, based on optical transmittance measurements as a function of carbon evolution, yields nearly identical estimates of the quantity of LAC and OC in OP.

\section{Summary}

Carbonaceous aerosols contribute $25-60 \%$ of the particulate concentrations found in CONUS. In routine monitoring programs such as IMPROVE, these complex molecules are usually categorized as OC and LAC and, in some cases, inorganic carbon in the form of calcium carbonate. The most common method of estimating LAC and OC concentrations is the thermal evolution procedures.

Investigations into the spatial and temporal variability of $R_{\mathrm{oc}}$, the ratio of organic mass to OC, using regressions of $\mathrm{PM}_{2.5}$ as the dependent and aerosol mass species as independent variables show that annual average $R_{\mathrm{Oc}}$ is increasing across all of CONUS, from about 1.6 to near 2.0, at an average statistically significant rate of about $0.02 \pm 0.008 /$ year.

Over this time period, average OC, OP, and LAC have decreased by about $20 \%, 60 \%$, and $45 \%$ respectively. For the most part, the highest and lowest $\mathrm{OC}$ concentrations are found in the eastern and western United States, respectively, with Midwestern locations having intermediate concentrations.

The relative change in $\mathrm{OP}$ and $\mathrm{OC}$ is highlighted by a statistically decreasing trend in the $\mathrm{OP} / \mathrm{OC}$ ratio over time in all regions of CONUS of about $-0.0087 \pm 0.002$ /year. The average CONUS OP/OC is 0.26 \pm 0.05 . Either OP is a mixture of carbon with a lower $R$ than $R_{\mathrm{oc}}$ or the $R$ for OL (organic carbon in OC other than $\mathrm{OP}, R_{\mathrm{ol}}$ ) is decreasing because the chemical composition of atmospheric carbon is changing, or both.

Assumptions concerning the composition of OP and trends in $R_{\mathrm{ol}}$ were further examined by exploring temporal trends in $R_{\mathrm{ol}}, R_{\mathrm{oc}}$, and $R_{\mathrm{ol}}-R_{\mathrm{oc}}$. Temporal trends in $R_{\mathrm{ol}}$ generally are not statistically significant and tend toward a constant value of between 2.0 to 2.2. $R_{\text {oc }}$, however, has statistically significant increasing trends, with $R_{\mathrm{oc}}$ approaching $R_{\mathrm{ol}}$ by 2017. In the East, over a 12-year period, the difference between $R_{\mathrm{ol}}$ and $R_{\mathrm{oc}}$ decreases by about 0.2 , approaching about 0.04 , with $R_{\mathrm{oc}}$ going from about 1.8 to 2.0.

$R_{\mathrm{Oc}}$ approaching $R_{\mathrm{ol}}$ as OP/OC decreases but well before OP/OC is zero, and a near constant $R_{\mathrm{ol}}$ suggests that OP is a mixture of OC-type material with an $R$ factor near that of OL and LAC or an LRC-type molecule. If the OC in OP has the same $R$ factor as OL and given $R_{\mathrm{ol}}, R_{\mathrm{oc}}$, and OL and OP concentrations, it is possible to estimate the fraction of OP that must be OL-type molecules to achieve the derived $R_{\mathrm{oc}}$ values. The average fraction of OP that is LAC over the entire CONUS is $34 \pm 0.05 \%$, resulting in an average CONUS-wide increase of LAC of $56 \pm 13 \%$, while the concurrent decrease in OC is $10 \pm 4 \%$.

The above analysis of the amount of LAC- and OC-type molecules in OP is based on an increasing temporal trend of $R_{\mathrm{Oc}}, R_{\mathrm{ol}}$ is not changing over time, and trends in the concentrations of OC, OP, OP/OC, and LAC. A second independent analysis technique based on optical transmittance measurements as a function of 
carbon evolution yields nearly identical estimates of the quantity of LAC and OC in OP. The agreement between corrected LAC (CLAC) and LAC derived from optical transmittance data is surprisingly good, with an OLS slope of $1.01 \pm 0.04$ and an $R^{2}=0.83$, further suggesting that reported LAC concentrations obtained using TOR are an underestimate of true LAC concentrations. Underreporting of LAC may alter supposed effects of LAC on climate forcing estimations, health effects, and estimates of haze.

As discussed in this work as well as many studies referenced above, the bifurcation of particulate carbon into OC and LAC fractions by thermal methods is problematic and subject to potential biases that can influence trends. These issues will likely increase as concentrations continue to decrease in the United States, challenging the detection limits of the TOR analyses. To overcome these issues, it may be necessary to incorporate other carbonaceous measurements in routine monitoring programs such as IMPROVE to continue to track trends of these important aerosol components.

\section{Acknowledgments}

IMPROVE (Interagency Monitoring of Protected Visual Environments) data are available for download (http://vista cira.colostate.edu/improve). IMPROVE is a collaborative association of state, tribal, and federal agencies, and international partners. The U.S. Environmental Protection Agency is the primary funding source, with contracting and research support from the National Park Service. The Air Quality Group at the University of California, Davis, is the central analytical laboratory, with ion analysis provided by Research Triangle Institute and carbon analysis provided by the Desert Research Institute. This work was funded by the National Park Service under Cooperative Agreement \#P14AC00728. The assumptions, findings, conclusions, judgments, and views presented herein are those of the authors and should not be interpreted as necessarily representing the National Park Service policies.

\section{References}

Aiken, A. C., Decarlo, P. F., Kroll, J. H., Worsnop, D. R., Huffman, J. A., Docherty, K. S., et al. (2008). O/C and OM/OC ratios of primary, secondary, and ambient organic aerosols with high-resolution time-of-flight aerosol mass spectrometry. Environmental Science \& Technology, 42(12), 4478-4485. https://doi.org/10.1021/es703009q

Bae, M. S., Demerjian, K. L., \& Schwab, J. J. (2006). Seasonal estimation of organic mass to organic carbon in PM2.5 at rural and urban locations in New York State. Atmospheric Environment, 40(39), 7467-7479. https://doi.org/10.1016/j.atmosenv.2006.07.008

Bae, M. S., Schauer, J. J., \& Turner, J. R. (2006). Estimation of the monthly average ratios of organic mass to organic carbon for fine particulate matter at an urban site. Aerosol Science and Technology, 40(12), 1123-1139. https://doi.org/10.1080/02786820601004085

Bond, T. C., \& Bergstrom, R. W. (2006). Light absorption by carbonaceous particles: An investigative review. Aerosol Science and Technology, 40(1), 27-67. https://doi.org/10.1080/02786820500421521

Boparai, P., Lee, J. M., \& Bond, T. C. (2008). Revisiting thermal-optical analyses of carbonaceous aerosol using a physical model. Aerosol Science and Technology, 42(11), 930-948. https://doi.org/10.1080/02786820802360690

Cachier, H., Bremond, M. P., \& Buat-Menard, P. (1989a). Determination of atmospheric soot carbon with a simple thermal method. Tellus Series B: Chemical and Physical Meteorology, 41(3), 379-390. https://doi.org/10.1111/j.1600-0889.1989.tb00316.x

Cachier, H., Bremond, M. P., \& Buat-Menard, P. (1989b). Thermal separation of soot carbon. Aerosol Science and Technology, 10(2), 358-364. https://doi.org/10.1080/02786828908959273

Cadle, S. H., Groblicki, P. J., \& Stroup, D. P. (1980). Automated carbon analyzer for particulate samples. Analytical Chemistry, 52(13), 2201-2206. https://doi.org/10.1021/ac50063a047

Cao, J. J., Lee, S. C., Ho, K. F., Zhang, X. Y., Zou, S. C., Fung, K., et al. (2003). Characteristics of carbonaceous aerosol in Pearl River Delta Region, China during 2001 winter period. Atmospheric Environment, 37(11), 1451-1460. https://doi.org/10.1016/s13522310(02)01002-6

Chan, T. W., Huang, L., Leaitch, W. R., Sharma, S., Brook, J. R., Slowik, J. G., et al. (2010). Observations of OM/OC and specific attenuation coefficients (SAC) in ambient fine PM at a rural site in central Ontario, Canada. Atmospheric Chemistry and Physics, 10(5), $2393-2411$. https://doi.org/10.5194/acp-10-2393-2010

Chow, J., Watson, J., Chen, L.W.A., Chang, O., \& Paredes-Miranda, G. (2005). Comparison of the DRI/OGC and Model 2001 thermal/optical carbon analyzers. For IMPROVE Steering Committee. Reno, Nevada: Desert Research Institute. January.

Chow, J. C., Watson, J. G., Chen, L. W. A., Arnott, W. P., \& Moosmuller, H. (2004). Equivalence of elemental carbon by thermal/optical reflectance and transmittance with different temperature protocols. Environmental Science \& Technology, 38(16), 4414-4422. https://doi. org/10.1021/es034936u

Chow, J. C., Watson, J. G., Chen, L. W. A., Chang, M. C. O., Robinson, N. F., Trimble, D., \& Kohl, S. (2007). The improve-a temperature protocol for thermal/optical carbon analysis: Maintaining consistency with a long-term database. Journal of the Air \& Waste Management Association, 57(9), 1014-1023. https://doi.org/10.3155/1047-3289.57.9.1014

Chow, J. C., Watson, J. G., Crow, D., Lowenthal, D. H., \& Merrifield, T. (2001). Comparison of IMPROVE and NIOSH carbon measurements. Aerosol Science and Technology, 34(1), 23-34. https://doi.org/10.1080/027868201300081923

Chow, J. C., Watson, J. G., Green, M. C., Wang, X., Chen, L. W. A., Trimble, D. L., et al. (2018). Separation of brown carbon from black carbon for IMPROVE and chemical speciation network $\mathrm{PM}_{2.5}$ samples. Journal of the Air \& Waste Management Association, 68(5), 494-510. https://doi.org/10.1080/10962247.2018.1426653

Chow, J. C., Watson, J. G., Lowenthal, D. H., Chen, L. W. A., \& Magliano, K. L. (2006). Particulate carbon measurements in California's San Joaquin Valley. Chemosphere, 62(3), 337-348. https://doi.org/10.1016/j.chemosphere.2005.04.094

Chow, J. C., Watson, J. G., Pritchett, L. C., Pierson, W. R., Frazier, C. A., \& Purcell, R. G. (1993). The DRI thermal optical reflectance carbon analysis system-Description, evaluation and applications in United States air-quality studies. Atmospheric Environment Part a-General Topics, 27(8), 1185-1201. https://doi.org/10.1016/0960-1686(93)90245-t

Davy, P. M., Tremper, A. H., Nicolosi, E. M. G., Quincey, P., \& Fuller, G. W. (2017). Estimating particulate black carbon concentrations using two offline light absorption methods applied to four types of filter media. Atmospheric Environment, 152, 24-33. https://doi.org/ 10.1016/j.atmosenv.2016.12.010

El-Zanan, H. S., Lowenthal, D. H., Zielinska, B., Chow, J. C., \& Kumar, N. (2005). Determination of the organic aerosol mass to organic carbon ratio in IMPROVE samples. Chemosphere, 60(4), 485-496. https://doi.org/10.1016/j.chemosphere.2005.01.005

El-Zanan, H. S., Zielinska, B., Mazzoleni, L. R., \& Hansen, D. A. (2009). Analytical determination of the aerosol organic mass-to-organic carbon ratio. Journal of the Air \& Waste Management Association, 59(1), 58-69. https://doi.org/10.3155/1047-3289.59.1.58

Fung, K. (1990). Particulate carbon speciation by $\mathrm{MnO}_{2}$ oxidation. Aerosol Science and Technology, 12(1), 122-127. https://doi.org/10.1080/ 02786829008959332

Gilardoni, S., Russell, L. M., Sorooshian, A., Flagan, R. C., Seinfeld, J. H., Bates, T. S., et al. (2007). Regional variation of organic functional groups in aerosol particles on four US East Coast platforms during the International Consortium for Atmospheric Research on Transport and Transformation 2004 campaign. Journal of Geophysical Research, 112, D10S27. https://doi.org/10.1029/2006JD007737 
Hallar, A. G., Lowenthal, D. H., Clegg, S. L., Samburova, V., Taylor, N., Mazzoleni, L. R., et al. (2013). Chemical and hygroscopic properties of aerosol organics at Storm Peak Laboratory. Journal of Geophysical Research: Atmospheres, 118, 4767-4779. https://doi.org/10.1002/ jgrd.50373

Hand, J. L., Prenni, A. J., Schichtel, B. A., Malm, W. C., \& Chow, J. C. (2019). Trends in remote PM2.5 residual mass across the United States: Implications for aerosol mass reconstruction in the IMPROVE network. Atmospheric Environment, 203, 141-152. https://doi.org/ 10.1016/j.atmosenv.2019.01.049

Hand, J. L., Schichtel, B. A., Malm, W. C., \& Frank, N. H. (2013). Spatial and temporal trends in PM2.5 organic and elemental carbon across the United States. Advances in Meteorology, Special Issue on Carbonaceous Particles in the Atmosphere: Experimental and Modeling Issues. https://doi.org/dx.doi.org/10.1155/2013/367674

Hand, J. L., Schichtel, B. A., Malm, W. C., \& Pitchford, M. L. (2012). Particulate sulfate ion concentration and $\mathrm{SO}_{2}$ emission trends in the United States from the early 1990s through 2010. Atmospheric Chemistry and Physics, 12, 10,353-10,365. https://doi.org/10.5194/acp-1210353-2012

Huntzicker, J. J., Johnson, R. L., Shah, J. J., \& Cary, R. A. (1982). Analysis of organic and elemental carbon in ambient aerosols by a thermal-optical method. In G. T. Wolff \& R. L. Klimisch (Eds.), Particulate carbon: Atmospheric life cycle (pp. 79-88). Boston: Springer. https://doi.org/10.1007/978-1-4684-4154-3_6

Joseph, D. B., Metza, J., Malm, W. C., \& Pitchford, M. L. (1987). A federal program to monitor visibility in class I areas. Paper presented at Air Pollution Control Association Annual Conference. Pittsburgh: Air Pollution Control Association.

Karanasiou, A., Minguillón, M. C., Viana, M., Alastuey, A., Putaud, J. P., Maenhaut, W., et al. (2015). Thermal-optical analysis for the measurement of elemental carbon (EC) and organic carbon (OC) in ambient air a literature review. Atmospheric Measurement Techniques Discussions, 8(9), 9649-9712. https://doi.org/10.5194/amtd-8-9649-2015

Kiss, G., Varga, B., Galambos, I., \& Ganszky, I. (2002). Characterization of water-soluble organic matter isolated from atmospheric fine aerosol. Journal of Geophysical Research, 107(D21), 8339. https://doi.org/10.1029/2001JD000603

Liu, S., Takahama, S., Russell, L. M., Gilardoni, S., \& Baumgardner, D. (2009). Oxygenated organic functional groups and their sources in single and submicron organic particles in MILAGRO 2006 campaign. Atmospheric Chemistry and Physics, 9(18), 6849-6863. https://doi. org/10.5194/acp-9-6849-2009

Long, C. M., Nascarella, M. A., \& Valberg, P. A. (2013). Carbon black vs. Black carbon and other airborne materials containing elemental carbon: Physical and chemical distinctions. Environmental Pollution, 181, 271-286. https://doi.org/10.1016/j.envpol.2013.06.009

Lowenthal, D., \& Kumar, N. (2006). Light scattering from sea-salt aerosols at Interagency Monitoring Of Protected Visual Environments (IMPROVE) sites. Journal of the Air \& Waste Management Association, 56(5), 636-642. https://doi.org/10.1080/10473289.2006.10464478

Lowenthal, D., Zielinska, B., Mason, B., Samy, S., Samburova, V., Collins, D., et al. (2009). Aerosol characterization studies at Great Smoky Mountains National Park, summer 2006. Journal of Geophysical Research, 114, D08206. https://doi.org/10.1029/2008JD011274

Lowenthal, D., Zielinska, B., Samburova, V., Collins, D., Taylor, N., \& Kumar, N. (2015). Evaluation of assumptions for estimating chemical light extinction at US national parks. Journal of the Air \& Waste Management Association, 65(3), 249-260. https://doi.org/10.1080/ 10962247.2014.986307

Mader, B. T., Flagan, R. C., \& Seinfeld, J. H. (2001). Sampling atmospheric carbonaceous aerosols using a particle trap impactor/denuder sampler. Environmental Science \& Technology, 35(24), 4857-4867. https://doi.org/10.1021/es011059o

Malm, W. C., \& Hand, J. L. (2007). An examination of aerosol physical and optical properties of aerosols collected in the IMPROVE program. Atmospheric Environment, 41, 3407-3427. https://doi.org/10.1016/j.atmosenv.2006.12.012

Malm, W. C., Schichtel, B. A., Ames, R. B., \& Gebhart, K. A. (2002). A ten-year spatial and temporal trend of sulfate across the United States. Journal of Geophysical Research, 107(D22), 4627. https://doi.org/10.1029/2002JD002107

Malm, W. C., Schichtel, B. A., Hand, J. L., \& Collett, J. L. (2017). Concurrent temporal and spatial trends in sulfate and organic mass concentrations measured in the IMPROVE monitoring program. Journal of Geophysical Research: Atmospheres, 122, 10,341-10,355. https://doi.org/10.1002/2017JD026865

Malm, W. C., Schichtel, B. A., \& Pitchford, M. L. (2011). Uncertainties in PM2.5 gravimetric and speciation measurements and what we can learn from them. Journal of the Air \& Waste Management Association, special Xi'an issue, 61, 1131-1149. https://doi.org/doi:10.1080/ 10473289.2001.603998

Malm, W. C., Sisler, J. F., Huffman, D., Eldred, R. A., \& Cahill, T. A. (1994). Spatial and seasonal trends in particle concentration and optical extinction in the United States. Journal of Geophyiscal Research, 99(D1), 1347-1370. https://doi.org/10.1029/93JD02916

Mizohata, A., \& Ito, N. (1985). Analysis of organic and elemental carbon in atmospheric aerosols by thermal method. Annual Report of the Radiation Center of Osaka Prefecture, 26, 51-55.

Nicolosi, E. M. G., Quincey, P., Font, A., \& Fuller, G. W. (2018). Light attenuation versus evolved carbon (AVEC)—A new way to look at elemental and organic carbon analysis. Atmospheric Environment, 175, 145-153. https://doi.org/10.1016/j.atmosenv.2017.12.011

NIOSH (1999). Method 5040 Issue 3 (Interim): Elemental carbon (diesel exhaust). In NIOSH Manual of Analytical Methods (4th ed., pp. 1-9). Cincinnati: National Institute of Occupational Safety and Health.

Novakov, T. (1982). Characterization of aerosol sulfur, carbon, and nitrogen by ESCA and thermal-analysis. Transactions of the American Nuclear Society, 41, 193-193.

Petzold, A., Ogren, J. A., Fiebig, M., Laj, P., Li, S. M., Baltensperger, U., et al. (2013). Recommendations for reporting "black carbon" measurements. Atmospheric Chemistry and Physics, 13(16), 8365-8379. https://doi.org/10.5194/acp-13-8365-2013

Polidori, A., Turpin, B. J., Davidson, C. I., Rodenburg, L. A., \& Maimone, F. (2008). Organic PM2.5: Fractionation by polarity, FTIR spectroscopy, and OM/OC ratio for the Pittsburgh aerosol. Aerosol Science and Technology, 42(3), 233-246. https://doi.org/10.1080/ 02786820801958767

Reff, A., Turpin, B. J., Offenberg, J. H., Weisel, C. P., Zhang, J., Morandi, M., et al. (2007). A functional group characterization of organic PM2.5 exposure: Results from the RIOPA study. Atmospheric Environment, 41(22), 4585-4598. https://doi.org/10.1016/j. atmosenv.2007.03.054

Rupprecht, G., Patashnick, H., Beeson, D. E., Green, R. N., \& Meyer, M. B. (1995). A new automated monitor for the measurement of particulate carbon in the atmosphere. In P. S. Bhardwaja (Ed.), U.S. EPA and Air \& Waste Management Association Conference on Particulate Matter: Health and Regulatory Issues (pp. 262-267). Pittsburgh: Air Pollution Control Association.

Russell, L. M. (2003). Aerosol organic-mass-to-organic-carbon ratio measurements. Environmental Science \& Technology, 37(13), 2982-2987. https://doi.org/10.1021/es026123w

Russell, L. M., Bahadur, R., \& Ziemann, P. J. (2011). Identifying organic aerosol sources by comparing functional group composition in chamber and atmospheric particles. Proceedings of the National Academy of Sciences of the United States of America, 108(9), 3516-3521. https://doi.org/10.1073/pnas.1006461108 
Russell, L. M., Takahama, S., Liu, S., Hawkins, L. N., Covert, D. S., Quinn, P. K., \& Bates, T. S. (2009). Oxygenated fraction and mass of organic aerosol from direct emission and atmospheric processing measured on the R/V Ronald Brown during TEXAQS/GOMACCS 2006. Journal of Geophysical Research, 114, D00F05. https://doi.org/10.1029/2008JD011275

Ruthenburg, T. C., Perlin, P. C., Liu, V., McDade, C. E., \& Dillner, A. M. (2014). Determination of organic matter and organic matter to organic carbon ratios by infrared spectroscopy with application to selected sites in the IMPROVE network. Atmospheric Environment, 86, 47-57. https://doi.org/10.1016/j.atmosenv.2013.12.034

Sharma, S., Brook, J. R., Cachier, H., Chow, J., Gaudenzi, A., \& Lu, G. (2002). Light absorption and thermal measurements of black carbon in different regions of Canada. Journal of Geophysical Research, 107(D24), 4771. https://doi.org/10.1029/2002JD002496

Simon, H., \& Bhave, P. V. (2012). Simulating the degree of oxidation in atmospheric organic particles. Environmental Science \& Technology, 46(1), 331-339. https://doi.org/10.1021/es202361w

Simon, H., Bhave, P. V., Swall, J. L., Frank, N. H., \& Malm, W. C. (2011). Determining the spatial and seasonal variability in om/oc ratios across the US using multiple regression. Atmospheric Chemistry and Physics, 11(6), 2933-2949. https://doi.org/10.5194/acp-11-2933-2011

Sun, Y., Zhang, Q., Macdonald, A. M., Hayden, K., Li, S. M., Liggio, J., et al. (2009). Size-resolved aerosol chemistry on Whistler Mountain, Canada with a high-resolution aerosol mass spectrometer during INTEX-B. Atmospheric Chemistry and Physics, 9(9), 3095-3111. https://doi.org/10.5194/acp-9-3095-2009

Tanner, R. L. (1982). An ambient experimental-study of phase-equilibrium in the atmospheric system - aerosol $\mathrm{H}+, \mathrm{NH} 4+, \mathrm{SO} 4(2-)$, NO3--NH3(G), HNO3(G). Atmospheric Environment, 16(12), 2935-2942. https://doi.org/10.1016/0004-6981(82)90044-0

Turpin, B. J., \& Lim, H. J. (2001). Species contributions to PM2.5 mass concentrations: Revisiting common assumptions for estimating organic mass. Aerosol Science and Technology, 35(1), 602-610. https://doi.org/10.1080/02786820152051454

U.S. EPA (U.S. Environmental Protection Agency) (1999). Regional haze regulations: Final rule. Federal Register, 64(126), 35,714-35,774, 40 CFR Part 51, Docket No. A-95-38. https:/www.gpo.gov/fdsys/pkg/FR-1999-07-01/pdf/99-13941.pdf

VDI (Verein Deutscher Ingenieure) (1999). Measurement of soot (ambient air)—Thermographic determination of elemental carbon after thermal desorption of organic carbon. Report No. 2465 Part 2. Dusseldorf, Germany: Verein Deutscher Ingenieure.

Watson, J. G., Chow, J. C., \& Chen, L. W. A. (2005). Summary of organic and elemental carbon/black carbon analysis methods and intercomparisons. Aerosol and Air Quality Research, 5(1), 65-102. https://doi.org/10.4209/aaqr.2005.06.0006

Watson, J. G., Chow, J. C., Lowenthal, D. H., Pritchett, L. C., Frazier, C. A., Neuroth, G. R., \& Robbins, R. (1994). Differences in the carbon composition of source profiles for diesel-powered and gasoline-powered vehicles. Atmospheric Environment, 28(15), 2493-2505. https://doi.org/10.1016/1352-2310(94)90400-6

Yang, H., \& Yu, J. Z. (2002). Uncertainties in charring correction in the analysis of elemental and organic carbon in atmospheric particles by thermal/optical methods. Environmental Science \& Technology, 36(23), 5199-5204. https://doi.org/10.1021/es025672z

Yu, J. Z., Xu, J. H., \& Yang, H. (2002). Charring characteristics of atmospheric organic particulate matter in thermal analysis. Environmental Science \& Technology, 36(4), 754-761. https://doi.org/10.1021/es015540q

Yu, X. Y., Lee, T., Ayres, B., Kreidenweis, S. M., Collett, J. L. Jr., \& Malm, W. C. (2005). Particulate nitrate measurement using nylon filters. Journal of the Air \& Waste Management Association, 55(8), 1100-1110. https://doi.org/10.1080/10473289.2005.10464721 